\title{
Self-Employment and Business Cycle Persistence: Does the Composition of Employment Matter for Economic Recoveries?*
}

\author{
Alan Finkelstein Shapiro ${ }^{\dagger}$ \\ Universidad de los Andes
}

January 5, 2014

\begin{abstract}
Self-employment comprises an important share of employment in many countries. Recent studies document that self-employment expands during downturns, a fact that arises from higher transition rates out of unemployment and into self-employment in recessions. Furthermore, countries with higher self-employment shares exhibit lower output persistence over the business cycle. In this paper, I build a business cycle model with frictional labor markets where individuals can be self-employed or employed in salaried firms. I show that economies with larger self-employment shares exhibit faster recoveries following a negative economy-wide productivity shock. Differences in the ease of entry into self-employment as the economy recovers play a key role in explaining contrasting labor market and output dynamics. The model successfully captures some of the key cyclical patterns of self-employment, as well as the quantitative relationship between self-employment and cyclical output persistence in the data.
\end{abstract}

JEL Classification: E02, E24, E32

Keywords: Business cycles, labor search, institutions

*This paper was previously circulated as "Informal Self-Employment and Business Cycle Persistence: Does the Composition of Employment Matter for Economic Recoveries" and is part of my Ph.D. dissertation at the University of Maryland, College Park. I thank Borağan Aruoba, John Haltiwanger, John Shea, William Maloney, Pablo D'Erasmo, Sushant Acharya, Álvaro La Parra Pérez, Julie Mullen, as well as seminar participants in the Macroeconomics Dissertation Workshop at the University of Maryland, seminar participants at Universidad de los Andes, Colombia, the Federal Reserve Board, Syracuse University, the World Bank, and Banco de la República for valuable comments and feedback. Any errors are my own.

${ }^{\dagger}$ Contact information: Calle 19A No. 1-37 Este, Bloque W, Department of Economics, Universidad de los Andes, Bogotá, Colombia. Email: a.finkelstein@uniandes.edu.co. 


\section{Introduction}

Countries are well-known to exhibit differences in employment arrangements. While developed economies have high salaried employment and low self-employment shares, developing economies exhibit the opposite pattern (see Table 1 and Gollin, 2008). A number of studies document that a majority of the self-employed are independent workers with no salaried employees, who nonetheless account for an important share of employment, firms, and economic activity (ILO, 2002; Perry et al., 2007; Sanandaji, 2010; Kucera and Roncolato, 2008). Despite their small scale and limited capital usage, these individuals are often capitalconstrained and must rely on external financing from input suppliers and other informal sources (Beck et al., 2008).

Recent cross-country evidence highlights two more facts about self-employment. First, self-employment expands during downturns. Second, this expansion arises mainly from an increase in transitions from unemployment into self-employment in recessions (see Table 2 or Bosch and Maloney, 2008; and Loayza and Rigolini, 2011). ${ }^{1}$ The cyclical behavior of self-employment raises a number of questions: if selfemployment is a feasible outside option to salaried work during recessions, how does it alter labor market dynamics? If owner-only firms are created during downturns, does this affect the pace of recoveries from adverse shocks? If so, through what channels? Figure 1 shows that there is a negative relationship between the cyclical persistence of output and the share of self-employment in non-agricultural employment for a sample of developed and developing countries. ${ }^{2}$ This fact, documented here for the first time, suggests that self-employment may play an important role in business cycle dynamics, and particularly, economic recoveries.

In this paper, I build a business cycle model with frictional labor markets where individuals can be self-employed or employed in salaried firms. I use the model to shed light on the channels through which self-employment influences the pace of economic recoveries, and show that economies with higher self-employment shares exhibit faster recoveries from negative aggregate productivity shocks. This result

\footnotetext{
${ }^{1}$ Transitions from salaried employment into self-employment are mildly procyclical, while transitions from self-employment into unemployment are strongly countercyclical. Transitions from non-participation into selfemployment are almost acyclical (see Bosch and Maloney, 2008). A decomposition by type of employment similar to the one in Table 2 is not possible for most countries due to limited data on labor flows.

${ }^{2}$ This finding is in line with Calderón and Fuentes (2010) regarding the recovery speed in emerging market economies. I use PPP-adjusted real GDP for years 1985 through 2007 from the World Development Indicators (using Catini, Panizza, and Saades (2010) compilation, to compute the cyclical persistence of output. Cyclical persistence is measured as the first-order autocorrelation of cyclical annual real GDP where the cyclical component of real GDP is obtained using an HP filter with smoothing parameter 100, consistent with annual data. The data on the share of self-employment as a percent of non-agricultural employment is obtained from the OECD for years 2000 through 2007. The relationship between output persistence and self-employment in Figure 1 holds even after controlling for the level of development and other factors that may influence the persistence of output, such as government spending and openness. See Appendix B for details.
} 
hinges critically on whether self-employment is a feasible outside option to salaried work in downturns, and whether the ease of entry into self-employment changes as the economy recovers. This last fact makes the cyclicality of transition rates into self-employment particularly important for understanding how differences in the composition of employment affect business cycle dynamics. Rising entry into selfemployment during downturns is difficult to explain with existing business cycle models of entrepreneurship and liquidity constraints: if individuals require external financing to start and run their businesses, they should be less likely to enter self-employment during bad times, when credit conditions deteriorate and the availability of credit from financial intermediaries falls. A series of empirical studies underscore the relevance of supplier or interfirm trade credit as a major source of external financing for small firms. Furthermore, a related line of research suggests that trade credit initially expands in downturns (see Section 3). This evidence offers a way to reconcile the fact that transitions into self-employment increase in recessions. It also hints at two relevant connections between larger salaried-sector firms that act as input suppliers and small-scale, self-employed enterprises: the first one rooted in trade credit relationships, and the second one embedded in the labor market.

Table 1: Self-Employment Rates Around the World

\begin{tabular}{ccccc}
\hline \hline & Self-Employment & Min. & Max. & Obs. \\
\hline Africa & 45.5 & 11.6 & 88.7 & 26 \\
Asia & 31.5 & 5 & 75.4 & 15 \\
Latin America & 37.9 & 18.9 & 64.7 & 19 \\
Developed Countries & 14.3 & 6.7 & 28.6 & 23 \\
\hline
\end{tabular}

Source: OECD (2009).

Table 2: Cyclical Correlations of Employment and Job-Finding Rates with Output

\begin{tabular}{ccc}
\hline \hline Cyclical Correlation with Output: & Brazil & Mexico \\
\hline Self-Employment & $\mathbf{- 0 . 2 1 9}$ & $\mathbf{- 0 . 4 1 5}$ \\
Formal Salaried Employment & 0.616 & 0.780 \\
& & \\
Transition Rate from Unemployment to: & & \\
Self-Employment & $\mathbf{- 0 . 6 0 0}$ & $\mathbf{- 0 . 4 3 3}$ \\
Formal Salaried Employment & 0.652 & 0.798 \\
\hline
\end{tabular}

Notes: Taken directly from Bosch and Maloney (2008). Self-employment corresponds to informal self-employment (ownaccount workers and business owners with less than 5 employees) as a share of the working-age population. The authors use quarterly data, and all variables are logged and HP-filtered with smoothing parameter 1600. Entry into informal (unprotected) salaried employment from unemployment is procyclical and therefore similar to formal salaried employment. 
Figure 1: Self-Employment and Cyclical Output Persistence Across Countries

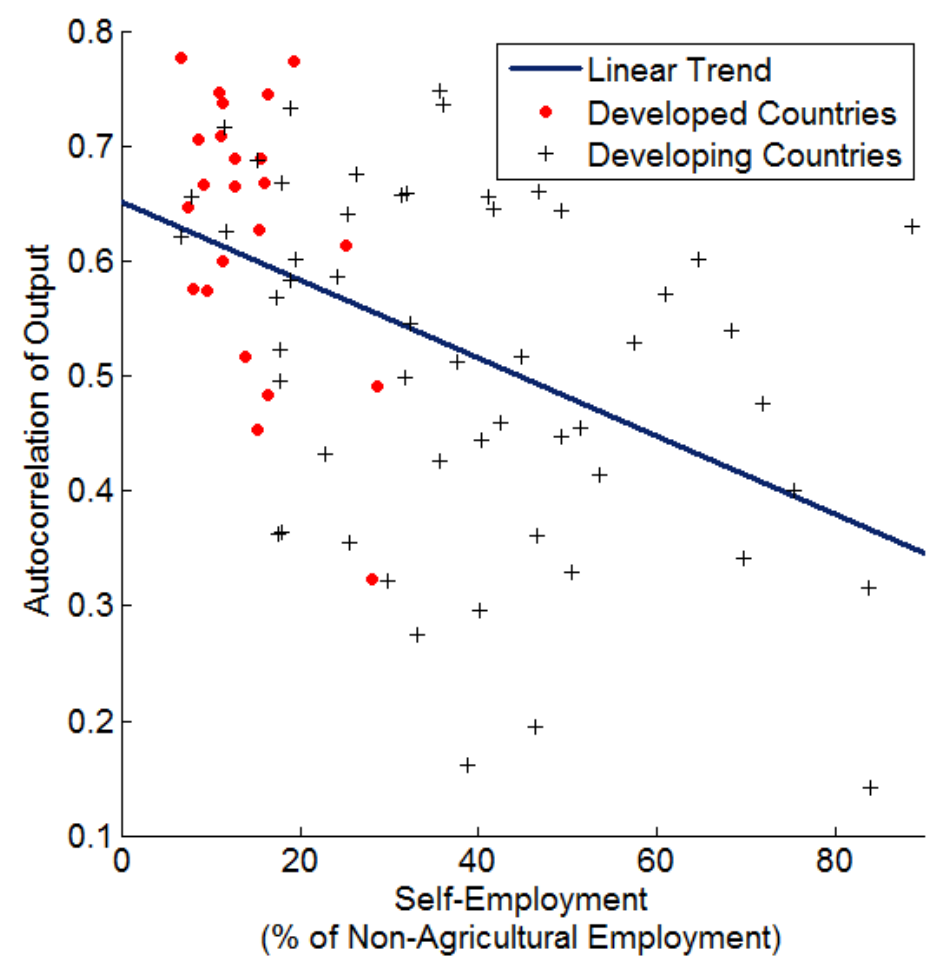

Notes: Author's calculations. The self-employment share corresponds to the average of annual self-employment as a percent of non-agricultural employment from 2000 to 2007. The autocorrelation of output corresponds to the first-order autocorrelation of the cyclical component of log annual PPP-adjusted real GDP from 1985 to 2007, using an HP filter with smoothing parameter 100. See Appendix B for more details.

Indeed, if self-employment is an attractive alternative to salaried work, fluctuations in the ease of entry into self-employment can affect salaried labor market dynamics in important ways. In economies with higher self-employment shares, self-employment is likely to exert more influence on overall labor market conditions since the structure of labor markets is tilted towards low-scale, owner-only firms. The fact that self-employment has a larger presence in the labor market modifies the decisions of salaried firms and households in the wake of economic fluctuations, which in turn shape the economy's response to shocks. This channel has not been explored in the existing literature.

In my framework, self-employment consists of own-account or independent workers who operate owneronly firms. ${ }^{3}$ I use these terms interchangeably throughout the paper to refer to individuals working on

${ }^{3}$ It is well known that self-employment exhibits substantial heterogeneity, with a small share of individuals running businesses that start small but grow rapidly. In this paper, I explicitly abstract from these individuals (often labeled entrepreneurs) and instead focus on those that run their own businesses without hiring salaried workers (which represent the majority of the self-employed) to explore whether the presence of an alternative employment state matters for business cycle dynamics. I consider the model in this paper as a stepping stone that 
their own who do not hire workers. ${ }^{4}$ Furthermore, the self-employed rely on capital from input suppliers to produce. Since supplier credit is a relationship-based source of financing, capital matching frictions present a natural modeling choice to capture the difficulty in obtaining capital to finance self-employment ventures. I assume that unemployed individuals must match with a capital supplier to enter self-employment. This process is costly and time-consuming. Salaried firms act as trade credit suppliers by devoting unused capital in the salaried sector to the self-employed in frictional capital markets. Capital search frictions play three crucial roles in my model: they establish a link between the salaried firms that supply capital and the self-employed who demand capital; they endogenize self-employment entry, where the supply and demand for capital determine the availability of self-employment capital and therefore the likelihood of becoming self-employed; and finally, they allow me to capture the countercyclicality of both the stock of self-employment and the entry rate into self-employment from unemployment in the data.

Two key features are critical to explaining the relationship between the share of self-employment and the pace of recoveries in the model. First, flows into self-employment respond to aggregate conditions and depend on the availability of capital used in self-employment. So, entry into self-employment is determined by the explicit decisions of households and firms in the economy, and will therefore change depending on the phase of the business cycle. Second, self-employment may not be a readily accessible alternative to salaried employment, since capital is needed to set up shop and finance production. Thus, differences in the ease of entry into self-employment will have direct static and dynamic consequences for the returns to salaried work, and therefore on the hiring and investment decisions in the salaried sector. Economies with higher self-employment shares tend to have lower capital utilization rates in the salaried sector, and therefore a higher supply of capital to the self-employment sector. The higher the availability of these inputs to potential self-employed individuals, the more likely it is for an unemployed individual to enter self-employment, and the larger is the influence of the self-employment outside option on salaried wages and aggregate labor market conditions. This has important implications for the economy's response to negative aggregate shocks.

In standard models with frictional labor markets, the probability of entering salaried employment falls in downturns as firms cut back on vacancies. This result is present in my framework. However, inflows into self-employment increase in recessions as capital utilization in the salaried sector falls and hence the availability of unused capital for self-employment increases. The expansion in self-employment takes place even though demand for self-employment capital also increases during downturns. In economies

can easily be expanded to account for those self-employment who eventually expand their firms by hiring workers.

${ }^{4}$ The International Labor Organization (ILO) considers own-account workers excluding (high-skilled) professionals; unpaid family workers; and business owners with less than five employees as "informal self-employed". 
with higher average self-employment shares, the self-employment outside option exerts more influence on labor market conditions, and its improvement at the onset of recessions lessens the initial fall in salaried wages when a negative aggregate shock hits the economy. Salaried firms in these economies respond by reducing vacancies and the share of capital used in production by more, causing a larger initial contraction in investment, salaried output, and total output when the shock hits the economy.

As aggregate productivity slowly returns to trend, salaried firms adjust their capital usage upwards more drastically relative to economies with less self-employment to take advantage of the recovery in aggregate productivity, which sharply curtails the initial increase in the availability of capital to the selfemployed. This makes the increase in the entry rate into self-employment less persistent after the shock in economies with higher steady-state self-employment. Since the increase in the likelihood of moving into self-employment in these economies is more short-lived, and self-employment has a larger presence in these economies, the initial fall in wages becomes more persistent following the shock. This occurs since the deterioration in the self-employment outside option puts downward pressure on salaried sector wages, much more so in economies with higher average self-employment. A more prolonged fall in wages coupled with a recovery in aggregate productivity creates a larger benefit from hiring workers, which in turn bolsters hiring and investment in the salaried sector. The faster recovery in salaried employment and investment boosts salaried sector output and translates into a faster recovery in total output in the economy. Thus, the model suggests that changes in the ease of entry into self-employment after a negative shock play a critical role in shaping the recovery path of wages in the salaried sector. This affects firms' hiring and investment decisions in the salaried sector, and the recovery of output in the economy. This is an important mechanism that can explain why economies with more self-employment recover faster from downturns in the model. In particular, this last fact cannot be explained if the likelihood of becoming self-employed is fixed over the business cycle. Finally, I show that the model can successfully capture the empirical relationship between output persistence and self-employment shown in Figure 1. This gives additional validity to the framework used to capture self-employment that I propose in the paper.

My work expands on two different literatures. The recent theoretical literature on labor flows in developing countries, rooted in the Mortensen and Pissarides search and matching framework, has generally abstracted from modeling self-employment (see Albrecht, Navarro, and Vroman, 2006; Bosch and Esteban-Pretel, 2012, among others). Similarly, the business cycle labor search literature has placed little attention on the role of self-employment in business cycle dynamics. I offer a tractable way to introduce self-employment in a business cycle search environment that explicitly accounts for endogenous transition rates into self-employment. To my knowledge, this is the first paper to capture important stylized facts 
about the cyclical behavior of self-employment in a business cycle framework with frictional labor markets.

The rest of the paper is organized as follows. Section 2 offers a summary of related literature and Section 3 presents four stylized facts on small firms and capital constraints. These facts motivate how I introduce endogenous and frictional entry into self-employment in the model, which I present in Section 4. Section 5 describes the calibration of the model, Section 6 discusses the simulation results, and Section 7 concludes.

\section{Related Literature}

Using data for 22 OECD countries, Koellinger and Thurik (2009) find that entrepreneurship is highly responsive to aggregate shocks, increasing during recessions when outside employment options become more scarce. These results are in line with Loayza and Rigolini (2011), who show that self-employment is on average countercylical using a large sample of developed and developing countries. ${ }^{5}$ Using Argentinian data, Mandelman and Montes-Rojas (2009) find that transitions into self-employment are higher during downturns, and the probability of becoming self-employed is increasing in the length of the downturn. They find that most self-employed workers are own-account workers with no employees, in line with the evidence for other countries documented in ILO (2002) and Perry et al. (2007).

Kumar and Schuetze (2007) use a partial equilibrium labor search model where transitions from unemployment into self-employment depend positively on the job-finding probability for salaried workers, and the self-employed do not require external resources to produce. They analyze the steady state impact of unemployment insurance, minimum wages, and taxation on self-employment, and their main focus is on business owners who hire workers. ${ }^{6}$ While they do not analyze business cycle dynamics, the entry rate into self-employment would be procyclical in their model. Also, in contrast to my framework, the salaried wage in their model is independent of conditions in self-employment. This last fact eliminates the key channel through which self-employment affects aggregate dynamics in my model. Rissman (2007) presents a search model with salaried employment and own-account work (i.e., self-employed individuals with owner-only businesses) to analyze the influence of startup costs on employment transitions. She posits a probability of receiving a business idea linked to a stochastic profit that individuals observe before deciding to become self-employed given current conditions in the labor market. ${ }^{7}$ My modeling approach endogenizes

\footnotetext{
${ }^{5}$ The authors also show that the countercylicality of self-employment is decreasing in the level of self-employment.

${ }^{6}$ One of their extensions addresses own-account work, but the endogenous transition rate from unemployment into self-employment in their benchmark model - which is driven by the job-finding rate in salaried work - does not change when they consider entry into own-account work.

${ }^{7}$ Individuals entering self-employment must pay a fixed startup cost, but no resources are needed to operate in self-employment thereafter. Hobijn and Şahin (2007) have a similar framework with business idea shocks and
} 
the transition rate into self-employment by linking it to tightness in physical capital markets and hence the availability of resources needed to start production. Access to capital has been shown to be an important constraint for starting small business ventures. Endogenous transition rates into self-employment add a dynamic component to the self-employment outside option absent in other frameworks, and the latter ultimately affects salaried wages when the economy is subject to shocks. This channel is crucial in explaining the link between economic recoveries and self-employment in the model. Lastly, Narita (2010) introduces informal self-employment into a life-cycle partial-equilibrium labor search environment with formal and informal salaried labor. ${ }^{8}$ Transitions into self-employment require prior experience in salaried employment to learn about potential ability to be self-employed. I propose an alternative way of introducing self-employment in a search environment that is more suitable for the analysis of business cycles, where I can account for the empirical relevance of external resources required for production during self-employment.

Den Haan, Ramey and Watson (2003) use capital matching frictions to model long-term relationships between borrowers (entrepreneurs) and lenders (financial intermediaries) and analyze the propagation of aggregate shocks. In their framework, households channel savings through financial intermediaries while entrepreneurs match with lenders to obtain funds for production. ${ }^{9}$ In contrast, Kurmann and PetroskyNadeau (2007) explore the role of capital frictions as a propagation mechanism in an environment without financial intermediaries. ${ }^{10}$ In a similar vein, Nicoletti and Pierrard (2006) propose an RBC model with labor and capital search frictions in which small firms match with banks to obtain capital before hiring workers, while large firms face frictionless capital markets. Their setup yields a procyclical probability of finding a financial intermediary that supplies capital. In contrast to these papers, I focus on the behavior of own-account work and its influence on labor market and output dynamics. I also eliminate financial intermediaries and assume a direct lending relationship between salaried firms supplying capital

occupational choice. Individuals with an idea above a given threshold become entrepreneurs subject to labor search frictions to hire workers. The authors abstract from owner-only firms and focus on steady state outcomes. For a related setup to Rissman (2007), see Rissman (2003), where self-employment is assumed to be a second-best alternative to salaried employment, where individuals can optimally search for salaried employment from selfemployment. In this setup, entry into self-employment depends solely on paying a fixed cost. It still takes one period to become officially self-employed. Exit from self-employment depends on whether search by the self-employed yields an acceptable wage offer in salaried employment.

${ }^{8}$ Margolis, Navarro, and Robalino (2012) and Bargain et al. (2012) introduce informal self-employment in a partial equilibrium search environment with formal and informal salaried employment. In these papers, as in Rissman $(2003,2007)$, self-employment opportunities arise randomly each period, after which individuals decide whether or not to enter self-employment. None of these papers address the business cycle implications of selfemployment.

${ }^{9}$ In contrast to other papers modeling the search for capital, their model includes asymmetric information and other contracting rigidities that complement search frictions.

${ }^{10}$ For an optimal policy approach, see Arseneau, Chugh, and Kurmann (2008). 
and the self-employed. Finally, my framework yields a countercyclical probability of finding a capital supplier, which is a key component needed to generate important cyclical differences in wage dynamics, salaried employment, and output in the model. To the best of my knowledge, my model is the first to capture the cyclicality of the transition rate from unemployment into self-employment observed in the data. Furthermore, I show that cyclical fluctuations in this transition rate have important implications for labor market and business cycle dynamics.

Fiess, Fugazza, and Maloney (2010) propose a small open economy general equilibrium model where the informal self-employed are subject to entry barriers in the form of liquidity constraints. Their work highlights the importance of identifying the sources of shocks to understand the cyclical movements in informal self-employment, since the latter depend on the type of shock affecting the economy. I emphasize search for productive inputs as an entry barrier to self-employment, focus on the implications of selfemployment for the cyclical persistence of output in a closed economy setting, and investigate the model's implications quantitatively. My model can capture the main argument in Fiess et al. (2010) by including a sectoral productivity shock in self-employment.

Finally, Bergoeing, Loayza, and Repetto (2004) argue that regulatory impediments distort the resource reallocation process among firms in the aftermath of adverse aggregate shocks, thereby leading to slower recoveries. They suggest that policies and regulations that push otherwise inefficient firms to stay in the market during downturns can lead to slower recoveries by distorting the restructuring process that takes place during recessions. My paper is related to Bergoeing et al.'s in that countries with high selfemployment have many small inefficient firms and a weaker institutional environment that adversely affects productivity in the salaried sector. I show that, despite an expansion of the low-productivity sector in recessions, economies with more self-employment exhibit faster recoveries from aggregate shocks.

\section{Capital Frictions and Self-Employment: The Role of Input Suppliers}

In this section, I outline four facts established by previous literature that motivate the use of capital search frictions to model entry into self-employment.

Frictions in obtaining capital affect firm creation and financing Blanchflower (2004) documents that frictions in obtaining capital are an important obstacle for small-firm creation in the United Kingdom and other developed countries. Other studies show that micro and small firms - a large majority of which are owner-only - tend to be more credit constrained and are more likely to consider access to credit as a major obstacle relative to medium and large firms (Kantis et al., 2002; IDB, 2005a; Cull, McKenzie, and 
Woodruff, 2008).

\section{Trade and supplier credit is a major source of financing for small firms Chavis, Klapper, and} Love (2011) use a sample of more than 100 countries and document that young firms in developing and developed countries tend to rely more on trade credit from input suppliers, friends and family, and informal lenders. ${ }^{11}$ Input suppliers and customers act as important sources of working capital for both young and older firms (Kuntchev et al., 2012), and are one of the most relevant sources of financing among small nascent firms in Latin America and Asia (IDB, 2005b). ${ }^{12}$ These are two regions where interfirm trade credit is particularly prevalent as a source of external finance and working capital for small firms (Demirgüç-Kunt and Maksimovic, 2001; Beck, Demirgüç-Kunt, and Maksimovic, 2008).

Supplier credit often involves goods and not cash loans Poor institutional quality in developing countries worsens access to formal credit and pushes young firms to tap informal financing sources (McMillan and Woodruff, 1999). A deficient institutional environment in these economies, combined with the asymmetric information problems intrinsic to lending relationships, makes credit based on goods in-kind or input credit - more prevalent than cash-based credit since goods are easier to monitor than cash loans (Burkart and Ellingsen, 2004). Relatedly, Eisfeldt and Rampini (2009) show that in the U.S., many small firms lease a substantial amount of capital to finance their operations, confirming that input credit and input leasing through suppliers and customers are important sources of external finance in developed countries as well. ${ }^{13}$

Trade credit tends to be countercyclical Ramey (1992) suggests that trade credit is countercyclical in the U.S. Using evidence on Mexico and East Asia, Love, Preve, and Sarria-Allende (2007) find that trade credit provision to firms by suppliers increases right after a financial crisis, and then falls in the aftermath, suggesting that trade credit is countercyclical. Using the World Bank's Financial Crisis Survey, Klapper and Randall (2011) document that a non-negligible fraction of firms in Eastern European countries

\footnotetext{
${ }^{11}$ For a comprehensive review of trade credit in the U.S., see Petersen and Rajan (1997). For evidence on the extent of trade credit across countries, see Brown, Chavis, and Klapper (2011) and Kuntchev et al. (2012). Klapper, Laeven, and Rajan (2011) cover in detail the characteristics of trade credit contracts. McMillan and Woodruff (1999) analyze the use of trade credit in Vietnam. Fabbri and Klapper (2009) have a related study on China. Hall and Monge-Naranjo (2003) present evidence on trade-credit use by Costa Rican manufacturing firms.

${ }^{12}$ Chavis, Klapper, and Love (2010) find that only 15 percent of young firms in low-income countries use formal banking as a source of financing. Credit through input suppliers is also used to avoid the regulatory burden that often characterizes formal credit relations (IDB, 2005b; Safavian and Wimpey, 2007).

${ }^{13}$ As Chavis, Klapper, and Love (2011) point out, leasing is different from trade credit since the former is typically backed by assets, and hence more prevalent in developed economies. However, both leasing and trade credit seem to involve establishing a (long-term) relationship of some sort with input suppliers.
} 
extended supplier credit during the 2008-2009 financial crisis. The countercyclicality of trade credit may offer one way to rationalize the countercyclicality of self-employment, since the self-employed rely on trade credit to operate their firms. Furthermore, input credit is often used to manage inventories (Mateut, Mizen, and Ziane, 2011), which tend to increase during downturns. Finally, Gal and Pinter (2013) document that capital renting is often countercyclical.

I take the facts above as supporting evidence for using capital search frictions to model self-employment: entry into the sector requires external finance through in-kind trade credit. Since trade credit relationships take time to materialize and are often long-lived, capital search frictions are a natural way to model frictional and endogenous transition rates into self-employment.

\section{The Model}

The economy is comprised of households and salaried firms. Salaried firms hire wage workers in frictional labor markets and accumulate capital. In contrast to the standard RBC labor search model, these firms also make a capital allocation decision: each period, they decide on the fraction of capital used inside the firm. Any unused capital is devoted to matching with potential self-employed individuals outside the firm, who use matched capital to produce in self-employment. All goods in the economy are identical. A representative household with many family members posts self-employment projects to attract capital in frictional capital markets, and sends its members to find salaried employment. There is perfect riskpooling in the economy. There is no on-the-job search and search for salaried employment is undirected. Separations from salaried employment and self-employment are exogenous. Lump-sum taxes are used to finance unemployment benefits. I focus on urban labor markets and therefore abstract from selfemployment in the agricultural sector.

The search process for the self-employed works in the following way: each period, after stochastic productivity is realized and separations from each employment state take place, the household chooses the number of self-employment projects posted today as well as the measure of self-employed individuals it would like to have producing next period. At the same time, salaried firms accumulate capital in a frictionless environment and choose the fraction of capital to be used for production inside the firm, which determines the fraction of capital available for matching with self-employment projects. The capital supplied by salaried firms can be considered as input trade credit to the self-employed. ${ }^{14}$ A matching function brings together unused salaried firm capital and potential projects and determines the creation

\footnotetext{
${ }^{14} \mathrm{An}$ equally valid way to interpret this is to assume that firms offer funds to the self-employed, where the funds are considered a "productive input" (den Haan, Ramey and Watson, 2003).
} 
of productive self-employment ventures. Capital market tightness is defined as the ratio of self-employment projects (capital demand) to the salaried firms' supply of unused capital for matching (capital supply). A tighter capital market implies that households find it more difficult to match with capital suppliers, which in turn lowers the probability of entering self-employment. Each self-employed individual requires one unit of capital to produce, so the measure of self-employed individuals in the current period is given by last period's amount of newly matched capital plus the stock of last period's self-employed individuals remaining after exogenous separations have taken place.

A successful match allows the self-employed to access a stochastic production technology that depends on an aggregate technology shock and a sectoral shock that reflects the additional volatility of the sector. ${ }^{15}$ For each unit of matched capital, households must supply one inelastic unit of self-employed labor for production to take place. To focus on the behavior of the self-employed, I abstract from the reasons why the self-employed do not expand their projects by hiring salaried workers since most self-employed run owner-only businesses. Salaried firms rent the matched capital to the self-employed while retaining full ownership during the length of the match. The rental rate paid by self-employed household members is determined by Nash bargaining between the self-employed individual and the firm. This setup captures the fact that establishing a trade credit relationship is costly and time-consuming and characterizes the prevalence of external financing barriers for new firms. ${ }^{16}$

The timing of events is as follows: at the beginning of the period, the productivity shocks are realized. Separations in all employment states take place and unemployment is determined. Salaried firms recover the capital separated at the beginning of the period and cover the depreciation of capital in surviving self-employment relationships. Firms also post salaried vacancies, choose the fraction of the capital stock used inside the firm, and choose investment. They also choose next period's salaried employment and self-employment capital. At the same time, households post self-employment projects and decide on next period's self-employment capital. Matching in labor and physical capital markets takes place. Firms and salaried workers bargain over wages while firms and the self-employed bargain over the rental rate on capital. Finally, production takes place, workers receive wage payments, and the self-employed pay the rental rate to firms.

\footnotetext{
${ }^{15}$ This sectoral shock plays an important role when comparing the prediction of the model against the data as it allows me to introduce additional volatility in the self-employment sector. The shock also generates differences in the volatility of self-employment earnings relative to wage earnings, which is supported by empirical evidence.

${ }^{16}$ Informational asymmetries may distort trade credit relationships as well, but these can be overcome with time. I abstract from information frictions to keep the model tractable.
} 


\subsection{Households}

As in Andolfatto (1996), I assume an infinitely-lived representative household of measure one, consisting of a large number of family members with perfect risk-pooling across household members. Within the household, individuals can be in salaried employment, self-employment (i.e., own-account or independent work), or unemployment. There is no labor force participation margin and labor supply is perfectly inelastic. Utility only depends on an aggregate consumption good whose price is normalized to one. Households cannot accumulate capital but they are the final owners of salaried firms in the economy. ${ }^{17}$ To move into self-employment, potential self-employed household members must be matched to salaried firms to rent capital for their projects. This is a key distinction from Arseneau, Chugh, and Kurmann (2008) and Kurmann and Petrosky-Nadeau (2007), where firms are the ones posting projects to attract capital in a frictional capital market. The household's problem is to choose paths of consumption $c_{t}$, total capital demand next period $k_{S E, t+1}^{h}$ (where each self-employed household member uses one unit of capital to produce), and potential self-employment projects $v_{S E, t}$ to

$$
\max _{\left\{c_{t}, k_{S E, t+1}^{h}, v_{S E, t}\right\}_{t=0}^{\infty}} E_{0} \sum_{t=0}^{\infty} \beta^{t}\left\{\frac{c_{t}^{1-\sigma}}{1-\sigma}\right\}
$$

subject to the budget constraint

$$
c_{t}+\psi_{S E} \kappa\left(v_{S E, t}\right)=\left(z_{t} a_{S E, t}-r_{S E, t}\right) k_{S E, t}^{h}+w_{S, t} n_{S, t}+\Pi_{S, t}-T_{t}+b u_{t}
$$

and the law of motion for capital used by the self-employed

$$
k_{S E, t+1}^{h}=\left(1-\delta^{S E}\right)\left(k_{S E, t}^{h}+v_{S E, t} p\left(\theta_{S E, t}\right)\right)
$$

where $\psi_{S E}$ is the resource cost of posting projects and $\kappa\left(v_{S E, t}\right)$ is a convex function of self-employment projects such that $\kappa^{\prime}\left(v_{S E, t}\right)>0$ and $\kappa^{\prime \prime}\left(v_{S E, t}\right)>0$. The term $\psi_{S E} \kappa\left(v_{S E, t}\right)$ can be considered as a start-up cost that the household pays to attract capital suppliers. This cost is required to move into

\footnotetext{
${ }^{17}$ This is similar to den Haan, Ramey, and Watson (2003), who assume that entrepreneurs use external funds from financial intermediaries and their own effort to produce. In other words, entrepreneurs cannot accumulate their own capital and must rely solely on external financing. An alternative would be to assume that the household accumulates capital but only uses part of it to finance the projects of the self-employed. The remaining amount would come from external sources such as trade credit. To keep the model tractable, I assume the potential self-employed rely solely on external finance. If the model included on-the-job search where individuals can move from wage employment into self-employment, then capital accumulation while on-the-job may be an alternative assumption to model transitions into self-employment. However, assuming some dependence on external financing or inputs suppliers is in line with the evidence on the constraints faced by small firms.
} 
self-employment but does not guarantee that the projects will become productive (i.e., regardless of the payment, there is a positive probability that some projects may not match with capital suppliers and hence may not become active). ${ }^{18}$ Total production in the self-employment sector is $y_{S E, t}=z_{t} a_{S E, t} k_{S E, t}^{h}$, which depends on matched capital, $k_{S E, t}^{h}$, aggregate productivity in the economy, $z_{t}$, and self-employment sectoral productivity, $a_{S E, t}$. Both $z_{t}$ and $a_{S E, t}$ follow independent stochastic processes. The shock $a_{S E, t}$ captures the additional volatility inherent to the self-employment sector (Maloney, Cunningham, and Bosch, 2004). ${ }^{19}$ Each self-employed individual uses a single unit of matched capital for production. Thus, $k_{S E, t}^{h}$ is also the measure of active self-employed individuals. Individual earnings for each self-employed member of the household are given by $\pi_{S E, t}=\left(z_{t} a_{S E, t}-r_{S E, t}\right) . w_{S, t}$ and $\Pi_{S, t}$ stand for the salaried sector wage and salaried firm profits, respectively. $b$ represents unemployment benefits. $\delta^{S E}$ is the exogenous separation rate for matched capital and $p\left(\theta_{S E, t}\right)=\frac{m_{S E}\left(v_{S E, t},\left(1-\omega_{t}\right) k_{S, t}\right)}{v_{S E, t}}$ is the probability of finding a capital supplier, where $m\left(v_{S E, t},\left(1-\omega_{t}\right) k_{S, t}\right)$ is a constant-returns-to-scale matching function that takes self-employment projects from households $v_{S E, t}$ and capital supply from salaried firms $\left(1-\omega_{t}\right) k_{S, t}$ as its inputs. Capital market tightness is defined as $\theta_{S E, t} \equiv \frac{v_{S E, t}}{\left(1-\omega_{t}\right) k_{S, t}}$. Note that a higher $\theta_{S E, t}$ implies a tighter capital market and corresponds to households finding it more difficult to match with a capital supplier. This reduces the unemployed's probability of entering self-employment, so that $p\left(\theta_{S E, t}\right)$ is a decreasing function of capital market tightness.

Since a household member who is matched to a firm in the capital market has access to the capital necessary to start production, self-employment $n_{S E, t}$ evolves in exactly the same way as $k_{S E, t}^{h}$, so that

$$
n_{S E, t+1}=\left(1-\delta^{S E}\right)\left(n_{S E, t}+m\left(v_{S E, t},\left(1-\omega_{t}\right) k_{S, t}\right)\right)
$$

The total employed labor force is given by

$$
n_{t}=n_{S, t}+n_{S E, t}
$$

where $n_{j, t}$ represents the labor measure in employment state $j=S, S E$. I normalize the total labor force to one and define unemployment as

$$
u_{t}=1-n_{S, t}-n_{S E, t}
$$

\footnotetext{
${ }^{18}$ This idea is similar to the cost that entrepreneurs have to pay during the initial phase of a project in den Haan and Kaltenbrunner (2009). Note that once a match with an input supplier occurs, $\psi_{S E}$ no longer has to be paid to maintain an existing relationship. Instead, matched self-employed individuals pay a rental rate on capital each period for as long as the relationship with the capital supplier lasts.

${ }^{19}$ In a setting with idiosyncratic shocks, this shock would capture project risk (see Akyol and Athreya, 2009, or Buera and Shin, 2011).
} 
Denote the representative household's instantaneous utility function by $U\left(c_{t}\right)=\frac{c_{t}^{1-\sigma}}{1-\sigma}$ and the marginal utility of consumption as $U_{c}\left(c_{t}\right)$. Combining first-order conditions yields the following self-employment project posting condition:

$$
\frac{\psi_{S E} \kappa^{\prime}\left(v_{S E, t}\right)}{p\left(\theta_{S E, t}\right)}=\left(1-\delta^{S E}\right) E_{t}\left\{\beta \frac{U_{c}\left(c_{t+1}\right)}{U_{c}\left(c_{t}\right)}\left(z_{t+1} a_{S E, t+1}-r_{S E, t+1}+\frac{\psi_{S E} \kappa^{\prime}\left(v_{S E, t+1}\right)}{p\left(\theta_{S E, t+1}\right)}\right)\right\}
$$

The left-hand side represents the expected marginal cost of looking for capital to start a project while the right-hand side captures the expected marginal benefit of matching with a salaried firm that supplies capital. The expected benefit includes both the benefit from producing with that unit of capital net of the cost of renting the unit of capital, $z a_{S E}-r_{S E}$, and the benefit of having the lending relationship continue into the future, i.e. the continuation value. Since households are the ultimate owners of the firms and for future reference, define $\Xi_{t \mid 0}=\beta^{t}\left(\frac{U_{c}\left(c_{t}\right)}{U_{c}\left(c_{0}\right)}\right)$ as the salaried firms' stochastic discount factor.

\subsection{Production}

The production sector is comprised of a salaried sector with firms that hire salaried workers in a frictional labor market and a self-employment sector with owner-only firms operated by the self-employed who use rented capital and their fixed effort to produce. This section focuses on the salaried firms' problem since the self-employed's problem was described above. Output from salaried firms is a function of salaried labor $n_{S}$, physical capital $k_{S}$, the share of capital used in production $\omega$, stochastic aggregate productivity $z$, and a time-invariant parameter $a_{S}$ meant to capture the quality of the institutional environment in the economy. Varying this parameter will affect the steady-state composition of employment in the economy. ${ }^{20}$ The firm's production function is assumed to be constant-returns-to-scale. Salaried sector production is given by

$$
y_{S, t}=z_{t} a_{S} f\left(n_{S, t}, \omega_{t} k_{S, t}\right)
$$

Since $\omega_{t}$ is the share of the firm's capital stock $k_{S, t}$ used in salaried production in period $t$, unused capital $\left(1-\omega_{t}\right) k_{S, t}$ represents the supply of capital for matching with the self-employed. Firms choose a sequence of vacancies for salaried employment $v_{S, t}$, salaried employment next period $n_{S, t+1}$, total capital next period $k_{S, t+1}$, the fraction of the capital stock used in production today $\omega_{t}$, and capital to be lent out to the

\footnotetext{
${ }^{20}$ This is a natural parameter to vary since the institutional setting of a country, particularly as it influences employment arrangements, affects mainly the salaried sector (Akyol and Athreya, 2009; Fiess et al., 2010). See Pietrobelli, Rabellotti and Aquilina (2004) and Ardagna and Lusardi (2008) for an overview of some of the main determinants of self-employment and entrepreneurship.
} 
self-employed next period $k_{S E, t+1}^{f}$ to

$$
\max _{\left\{v_{S, t}, n_{S, t+1}, k_{S, t+1}, \omega_{t}, k_{S E, t+1}^{f}\right\}_{t=0}^{\infty}} E_{0} \sum_{t=0}^{\infty} \Xi_{t \mid 0}\left\{\begin{array}{c}
z_{t} a_{S} f\left(n_{S, t}, \omega_{t} k_{S, t}\right)-w_{S, t} n_{S, t} \\
-\psi_{S} v_{S, t}-i_{t}+r_{S E, t} k_{S E, t}^{f}
\end{array}\right\}
$$

subject to the law of motion for salaried employment

$$
n_{S, t+1}=\left(1-\delta^{S}\right)\left(n_{S, t}+v_{S, t} q\left(\theta_{S, t}\right)\right)
$$

the evolution of capital used in the self-employment sector

$$
k_{S E, t+1}^{f}=\left(1-\delta^{S E}\right)\left(k_{S E, t}^{f}+\left(1-\omega_{t}\right) k_{S, t} q\left(\theta_{S E, t}\right)\right)
$$

and the evolution of the firm's total capital stock ${ }^{21}$

$$
\begin{array}{r}
k_{S, t+1}=i_{t}+(1-\delta) \omega_{t} k_{S, t}+\left(\delta^{S E}-\delta\right) k_{S E, t}^{f} \\
+\left[(1-\delta)\left(1-\omega_{t}\right) k_{S, t}-\left(1-\delta^{S E}\right)\left(1-\omega_{t}\right) k_{S, t} q\left(\theta_{S E, t}\right)\right]
\end{array}
$$

The term $\psi_{S} v_{S, t}$ captures the total cost of posting salaried vacancies. ${ }^{22}$ The salaried employment job-filling probability is $q\left(\theta_{S, t}\right)=\frac{m_{S}\left(u_{t}, v_{S, t}\right)}{v_{S, t}}$, where $m_{S}\left(v_{S, t}, u_{t}\right)$ is a constant-returns-to-scale matching function for salaried employment, $\delta^{S}$ is the separation rate for salaried workers, and $\delta^{S E}$ is the self-employment separation rate. The probability of finding a self-employment project is $q\left(\theta_{S E, t}\right)=\frac{m_{S E}\left(v_{S E, t},\left(1-\omega_{t}\right) k_{S, t}\right)}{\left(1-\omega_{t}\right) k_{S, t}}$, where once again $\theta_{S E, t}=\frac{v_{S E, t}}{\left(1-\omega_{t}\right) k_{S, t}}$ embodies tightness in the market for physical capital. Note that higher capital market tightness from the salaried firms' perspective means that firms find it easier to match their unused capital with self-employment projects. Thus, $q\left(\theta_{S E, t}\right)$ is increasing in $\theta_{S E, t}$. The expression $\left[(1-\delta)-\left(1-\delta^{S E}\right) q\left(\theta_{S E, t}\right)\right]\left(1-\omega_{t}\right) k_{S, t}$ captures the fact that firms subtract the capital matched in $t$ after taking into account separations, which is given by $\left(1-\delta^{S E}\right) q\left(\theta_{S E, t}\right)\left(1-\omega_{t}\right) k_{S, t}$, from the capital that was devoted to matching in $t$, net of depreciation, which is given by $(1-\delta)\left(1-\omega_{t}\right) k_{S, t}$. As in Kurmann and Petrosky-Nadeau (2007) and Arseneau et al. (2008), the firm considers unmatched capital as part of capital accumulation, net of depreciation. The term $\delta k_{S E, t}^{f}$ is an expense for the firm since capital in

\footnotetext{
${ }^{21}$ Note that combining the law of motion for capital held by the firm and the law of motion for capital in self-employment yields a standard law of motion for total capital in the economy.

${ }^{22}$ One can introduce a resource cost of supplying capital to proxy for the administrative and monitoring costs associated with the supply of input credit. Introducing such a cost does not change the main results of the paper. A similar comment applies to investment adjustment costs.
} 
self-employment depreciates each period, so the term must be subtracted from the capital available for allocation at the beginning of period $t+1$ after accounting for the capital that is returned to the firm due to separations, given by $\delta^{S E} k_{S E, t}^{f}$. For future reference, define $u_{k, t} \equiv\left(1-q\left(\theta_{S E, t}\right)\right)\left(1-\omega_{t}\right) k_{S, t}$ as unmatched idle capital before depreciation. Combining first-order conditions yields a standard job creation condition:

$$
\frac{\psi_{S}}{q\left(\theta_{S, t}\right)}=\left(1-\delta^{S}\right) E_{t} \Xi_{t+1 \mid t}\left\{\begin{array}{c}
z_{t+1} a_{S} f_{n_{S}}\left(n_{S, t+1}, \omega_{t+1} k_{S, t+1}\right) \\
-w_{S, t+1}+\frac{\psi_{S}}{q\left(\theta_{S, t+1}\right)}
\end{array}\right\}
$$

a standard Euler equation for capital $k_{S}$ :

$$
1=E_{t} \Xi_{t+1 \mid t}\left\{z_{t+1} a_{S} f_{\omega k_{S}}\left(n_{S, t+1}, \omega_{t+1} k_{S, t+1}\right)+(1-\delta)\right\}
$$

and a capital supply condition for capital allocated to matching with self-employment projects:

$$
\begin{gathered}
\frac{z_{t} a_{S} f_{\omega k_{S}}\left(n_{S, t}, \omega_{t} k_{S, t}\right)+\left(1-\delta^{S E}\right) q\left(\theta_{S E, t}\right)}{q\left(\theta_{S E, t}\right)}= \\
\left(1-\delta^{S E}\right) E_{t} \Xi_{t+1 \mid t} \quad\left\{\begin{array}{c}
r_{S E, t+1}+\left(\delta^{S E}-\delta\right) \\
+\frac{\left[z_{t+1} a_{S} f_{\omega k_{S}}\left(n_{S, t+1}, \omega_{t+1} k_{S, t+1}\right)+\left(1-\delta^{S E}\right) q\left(\theta_{S E, t+1}\right)\right]}{q\left(\theta_{S E, t+1}\right)}
\end{array}\right\}
\end{gathered}
$$

The job creation condition states that the expected marginal cost of a vacancy is equal to the expected marginal benefit of having a worker in the firm, which takes into account the continuation value since employment relationships are long-lived. The capital Euler equation balances the cost and benefit of obtaining an additional unit of capital, regardless of whether it is used within the firm or lent out to a self-employed individual.

The capital supply condition is similar but not identical to the one in Arseneau et al. (2008). The lefthand side gives the expected marginal cost of lending an additional unit of capital to self-employed workers. This cost includes the opportunity cost of devoting a unit of capital to matching, $z_{t} a_{S} f_{\omega k_{S}}\left(n_{S, t}, \omega_{t} k_{S, t}\right)$, which is the marginal product of capital used inside salaried firms. The second term captures the fact that if capital is matched today with probability $q\left(\theta_{S E, t}\right)$ and survives with probability $\left(1-\delta^{S E}\right)$, then the firm must set aside that capital and hence cannot count it as part of idle capital (after matching) within the firm. The right-hand side gives the expected benefit of a matched unit of capital. The benefit for the firm is the rental rate obtained if the relationship survives next period, net of the depreciation of capital $\delta$, which the firm must cover for surviving relationships. Also, the firm takes into account that the match ends with probability $\delta^{S E}$, in which case the firm gets back a unit of capital. The last term on the right-hand side reflects the continuation value of a long-term capital relationship. The intertemporal 
nature of the optimal capital supply decision arises due to the existence of long-term relationships between the self-employed and their input suppliers. Note that the capital supply condition is a decision made by the firm and not by the household, since salaried firms are the ones making capital accumulation decisions. Furthermore, the expected cost of investing capital in self-employment ventures will depend on the marginal product of capital within the firm since the firm faces a tradeoff between trying to match capital and using it in-house. These are two key distinctions relative to the setting in Arseneau et al. (2008).

\subsection{Labor Market Search, Capital Search, and Nash Bargaining}

The job-finding and job-filling rates are given by $p\left(\theta_{S, t}\right)=\frac{m_{S}\left(u_{t}, v_{S, t}\right)}{u_{t}}$ and $q\left(\theta_{S, t}\right)=\frac{m_{S}\left(u_{t}, v_{S, t}\right)}{v_{S, t}}$, respectively. Thus, salaried labor market tightness is $\theta_{S, t}=\frac{p\left(\theta_{S, t}\right)}{q\left(\theta_{S, t}\right)}$. The probability of finding a capital supplier is $p\left(\theta_{S E, t}\right)=\frac{m_{S E}\left(v_{S E, t},\left(1-\omega_{t}\right) k_{S, t}\right)}{v_{S E, t}}$ and the probability of finding a self-employment project is $q\left(\theta_{S E, t}\right)=$ $\frac{m_{S E}\left(v_{S E, t},\left(1-\omega_{t}\right) k_{S, t}\right)}{\left(1-\omega_{t}\right) k_{S, t}}$. Then, capital market tightness is $\theta_{S E, t}=\frac{q\left(\theta_{S E, t}\right)}{p\left(\theta_{S E, t}\right)}$.

\subsubsection{Household Value Functions}

The value function of a salaried worker currently employed at a firm, $\mathbf{W}_{S, t}$, is given by

$$
\mathbf{W}_{S, t}=\lambda_{t}^{h} w_{S, t}+E_{t} \beta\left\{\left(1-\delta^{S}\right) \mathbf{W}_{S, t+1}+\delta^{S} \mathbf{W}_{U, t+1}\right\}
$$

where labor income is weighted by the marginal utility of consumption, $\lambda_{t}^{h}=U_{c}\left(c_{t}\right)$. The value function of a self-employed individual currently matched with a capital supplier, $\mathbf{W}_{S E, t}$, is given by

$$
\mathbf{W}_{S E, t}=\lambda_{t}^{h}\left(z_{t} a_{S E, t}-r_{S E, t}\right)+E_{t} \beta\left\{\left(1-\delta^{S E}\right) \mathbf{W}_{S E, t+1}+\delta^{S E} \mathbf{W}_{U, t+1}\right\}
$$

To incorporate the probability of entry into self-employment in the value function of an unemployed individual, define $v_{S E, t}^{u} \equiv \frac{v_{S E, t}}{u_{t}}$, which gives the number of project postings per unemployed household member. Hence, the effective probability of finding a capital supplier per unemployed individual, which I denote by $p^{u}\left(\theta_{S E, t}\right)$, is given by $v_{S E, t}^{u} p\left(\theta_{S E, t}\right)$. The value function of an unemployed individual, $\mathbf{W}_{U, t}$, 
can then be written as

$$
\mathbf{W}_{U, t}=\lambda_{t}^{h} b+E_{t} \beta\left\{\begin{array}{c}
\left(1-\delta^{S}\right) p\left(\theta_{S, t}\right) \mathbf{W}_{S, t+1} \\
+\left(1-\delta^{S E}\right) v_{S E, t}^{u} p\left(\theta_{S E, t}\right) \mathbf{W}_{S E, t+1} \\
+\left[1-\left(1-\delta^{S}\right) p\left(\theta_{S, t}\right)\right. \\
\left.-\left(1-\delta^{S E}\right) v_{S E, t}^{u} p\left(\theta_{S E, t}\right)\right] \mathbf{W}_{U, t+1}
\end{array}\right\}
$$

where $b$ denotes unemployment benefits measured in consumption units. ${ }^{23}$

\subsubsection{Firm Value Functions}

The marginal value of a salaried firm from having a salaried worker, $\mathbf{J}_{S, t}$, is given by

$$
\mathbf{J}_{S, t}=z_{t} a_{S} f_{n_{S}}\left(n_{S, t}, \omega_{t} k_{S, t}\right)-w_{S, t}+E_{t} \Xi_{t+1 \mid t}\left\{\left(1-\delta^{S}\right) \mathbf{J}_{S, t+1}\right\}
$$

The marginal value of a salaried firm from renting a unit of capital to a self-employed household member is

$$
\mathbf{J}_{S E, t}=r_{S E, t}+\left(\delta^{S E}-\delta\right)+E_{t} \Xi_{t+1 \mid t}\left\{\left(1-\delta^{S E}\right) \mathbf{J}_{S E, t+1}\right\}
$$

where the firm takes into account that the credit relationship will survive into the next period with probability $\left(1-\delta^{S E}\right)$. Also, recall that firms must cover the depreciation of the matched unit of capital, $\delta$, but gain a unit of previously matched capital if it is separated with probability $\delta^{S E}$. This yields the term $\left(\delta^{S E}-\delta\right)$ in the expression for $\mathbf{J}_{S E, t}$ above. Finally, the value of having unused, idle capital is given by $\mathbf{J}_{u_{k}, t}=(1-\delta)$ since capital depreciates every period at rate $\delta$.

\subsubsection{Nash Bargaining: Wage and Rental Rate Determination}

Real wages for salaried workers are determined by Nash bargaining with salaried firms. The real wage $w_{S, t}$ solves

$$
\max _{w_{S, t}}\left\{\left(\frac{\mathbf{W}_{S, t}-\mathbf{W}_{U, t}}{\lambda_{t}^{h}}\right)^{\nu_{S}}\left(\mathbf{J}_{S, t}\right)^{1-\nu_{S}}\right\}
$$

\footnotetext{
${ }^{23}$ In principle, the expression for $\mathbf{W}_{U, t}$ suggests that it is possible for an unemployed individual to be matched simultaneously to more than one type of employment. Assuming otherwise would rule out closed-form solutions for the wage and the rental rate. Since these price expressions provide intuition for the influence of self-employment on wages (and therefore hiring), I assume that individuals can only be in a single type of employment at any given time after being matched. An alternative would be to fully account for the fact that, if there is a match in a given employment state, the same individual cannot be matched in the other employment state. This would imply that the wage in period $t$ can only be expressed as a function of each of the value functions in $t+1$ and no closed-form solutions could be obtained. The downside of this approach is that we would not be able to explicitly observe how the possibility of self-employment affects the wage and the capital rental rate.
} 
where $\left(\frac{\mathbf{W}_{S, t}-\mathbf{W}_{U, t}}{\lambda_{t}^{h}}\right)$ is the worker's surplus, $\mathbf{J}_{S, t}$ is the salaried firm's surplus, and $\nu_{S}$ is the worker's bargaining power. In a similar fashion, the Nash bargaining problem in the capital market is

$$
\max _{r_{S E, t}}\left\{\left(\frac{\mathbf{W}_{S E, t}-\mathbf{W}_{U, t}}{\lambda_{t}^{h}}\right)^{\nu_{S E}}\left(\mathbf{J}_{S E, t}-\mathbf{J}_{u_{k}, t}\right)^{1-\nu_{S E}}\right\}
$$

where the self-employed household member's surplus is $\left(\frac{\mathbf{W}_{S E, t}-\mathbf{W}_{U, t}}{\lambda_{t}^{h}}\right)$ and the salaried firm's surplus is $\left(\mathbf{J}_{S E, t}-\mathbf{J}_{u_{k_{s}}, t}\right)$, where the threat point is the value of unmatched, idle capital.

Using the first-order conditions from (21) and (22), the Nash bargaining solution for the wage and the rental rate can be shown to be $\mathrm{e}^{24}$

$$
\begin{aligned}
& w_{S, t}=\nu_{S}\left[z_{t} a_{S} f_{n_{S}}\left(n_{S, t}, \omega_{t} k_{S, t}\right)+\psi_{S} \theta_{S, t}\right]+\left(1-\nu_{S}\right) b \\
& +\frac{\left(1-\nu_{S}\right) \nu_{S E}}{1-\nu_{S E}} v_{S E, t}^{u} p\left(\theta_{S E, t}\right)\left[\frac{z_{t} a_{S} f_{\omega k_{S}}\left(n_{S, t}, \omega_{t} k_{S, t}\right)}{q\left(\theta_{S E, t}\right)}\right] \\
& +\frac{\left(1-\nu_{S}\right) \nu_{S E}}{1-\nu_{S E}} v_{S E, t}^{u} p\left(\theta_{S E, t}\right)\left(1-\delta^{S E}\right)\left[1-E_{t} \Xi_{t+1 \mid t}(1-\delta)\right]
\end{aligned}
$$

Similarly, the rental rate for matched capital is

$$
\begin{aligned}
& r_{S E, t}=\left(1-\nu_{S E}\right)\left[z_{t} a_{S E, t}-\frac{\nu_{S}}{1-\nu_{S}} \psi_{S} \theta_{S, t}-b\right] \\
& -\nu_{S E} v_{S E, t}^{u} p\left(\theta_{S E, t}\right)\left[\frac{z_{t} a_{S} f_{\omega k_{S}}\left(n_{S, t}, \omega_{t} k_{S, t}\right)}{q\left(\theta_{S E, t}\right)}\right] \\
& +\nu_{S E}\left(1-v_{S E, t}^{u} p\left(\theta_{S E, t}\right)\right)\left(1-\delta^{S E}\right)\left[1-E_{t} \Xi_{t+1 \mid t}(1-\delta)\right]
\end{aligned}
$$

The wage and the rental rate depend, among other things, on market tightness in the other employment state. Intuitively, in a model with search frictions and two types of employment, the prices of factors of production should not only depend on the marginal product of each of the factors but also on the potential opportunities in other employment states, which are embodied in market tightness in each of these states. Thus, salaried wages and the rental rate on capital used in self-employment are affected by the outside options available in the economy.

\footnotetext{
${ }^{24}$ Appendix $\mathrm{B}$ describes the derivation of the wage and rental rate equations.
} 


\subsubsection{Intuition Behind the Wage and Rental Rate Equations}

To understand better how conditions in one labor market spill over into other markets, consider the wage in the salaried sector. The wage equation in a standard one-sector search model without self-employment would be given by

$$
w_{S, t}=\nu_{S}\left[z_{t} a_{S} m p l_{S, t}+\psi_{S} \theta_{S, t}\right]+\left(1-\nu_{S}\right) b
$$

where $m p l_{S, t}$ is the marginal product of labor and $\nu_{S}$ is the bargaining weight for workers. Both higher labor market tightness $\theta_{S, t}$ and a higher outside option in unemployment $b$ lead to a higher wage.

Now, consider the expression for the wage in the economy with self-employment. To see how market tightness in the capital market - and hence the self-employment outside option - affects the wage, rewrite the last two lines of the wage equation as

$$
v_{S E, t}^{u} \frac{\left(1-\nu_{S}\right) \nu_{S E}}{1-\nu_{S E}}\left[\begin{array}{c}
\frac{z_{t} a_{S} f_{\omega k_{S}}\left(n_{S, t}, \omega_{t} k_{S, t}\right)}{\theta_{S E, t}}+ \\
p\left(\theta_{S E, t}\right)\left(1-\delta^{S E}\right)\left[1-E_{t} \Xi_{t+1 \mid t}(1-\delta)\right]
\end{array}\right]
$$

where recall that capital market tightness is defined as $\theta_{S E, t}=\frac{v_{S E, t}}{\left(1-\omega_{t}\right) k_{S, t}}$ and given constant-returns in matching, $\theta_{S E, t}=\frac{q\left(\theta_{S E, t}\right)}{p\left(\theta_{S E, t}\right)}$. The first term inside the brackets represents the foregone marginal product of capital if the capital devoted to matching were instead used inside the firm. The second element captures the fact that firms participating in the capital matching process must set aside $\left(1-\delta^{S E}\right)$ units of capital in the current period for those new matches that become productive next period, and must cover depreciation costs for matched capital next period. This second term is also part of the opportunity cost of successfully matching capital. Thus, it is weighted by the probability of a successful match from the household's perspective. This cost is $\left(1-\delta^{S E}\right)\left[1-E_{t} \Xi_{t+1 \mid t}(1-\delta)\right]$ since firms net out the depreciation of capital from the total opportunity cost of storing the capital today until it becomes productive next period. In summary, the term in brackets is akin to the vacancy posting cost for salaried employment, except that the cost of matching capital depends on the opportunity cost of capital and the cost of covering depreciation for capital relationships.

Having described each component of the wage, note that an increase in capital market tightness $\theta_{S E, t}$ ceteris paribus decreases the expected cost to the firm of devoting capital to matching. Given that the household's probability of finding a capital supplier $p\left(\theta_{S E, t}\right)$ is decreasing in $\theta_{S E, t}$, an increase in capital market tightness reduces an unemployed individual's probability of entering self-employment. ${ }^{25}$

\footnotetext{
${ }^{25}$ Clearly, an increase in $\theta_{S E, t}$ has implications for the marginal product of capital used inside the salaried firm if $\theta_{S E, t}$ changes due to $\left(1-\omega_{t}\right) k_{S, t}$. Thus, the impact of a change in $\theta_{S E, t}$ is more complex than what my description suggests. However, for the purposes of developing intuition about the wage and the rental rate, it proves useful to
} 
This implies that an increase in $\theta_{S E, t}$ reduces the salaried sector wage since the worker's outside option of going into self-employment is now less valuable. In other words, while an increase in salaried labor market tightness $\theta_{S, t}$ tends to push the wage up, an increase in capital market tightness $\theta_{S E, t}$ goes in the opposite direction since the latter implies a lower probability of moving into self-employment - and therefore a weaker outside option - from the point of view of household members.

Now consider the determinants of the capital rental rate for the self-employed. First, from equation (24), the rental rate depends positively on output of a given self-employed individual, $z_{t} a_{S E, t}$. This is similar to the wage equation, in which the wage is increasing in the marginal product of labor. Also, an increase in the value of the other two outside options for the household (unemployment or salaried employment) through higher salaried market tightness $\theta_{S, t}$ or a higher outside option $b$ puts downward pressure on the rental rate and increases self-employment earnings. Meanwhile, an increase in capital market tightness $\theta_{S E, t}$ puts upward pressure on the rental rate, since a tighter capital market reduces the matching probability for households $p\left(\theta_{S E, t}\right)$ and raises the capital matching probability for salaried firms $q\left(\theta_{S E, t}\right)$. Finally, note that a higher marginal product of capital for salaried firms increases the opportunity cost of devoting capital to matching, which pushes firms to decrease the supply of capital for matching. Since this increases $\theta_{S E, t}$ for a given number of self-employment projects, the impact on the rental rate is in principle ambiguous. However, note that a higher marginal product of capital also pushes firms to post more salaried vacancies, thereby increasing salaried labor market tightness. Higher labor market tightness, in turn, puts downward pressure on the rental rate. Then, we should expect the rental rate to be lower if the change in labor market tightness dominates the influence exerted by capital market tightness and the opportunity cost of capital on the rental rate. This discussion can be summarized as:

$$
w_{S, t}=\Theta_{S, t}\left(\underset{(+)}{m p l_{S}}, \underset{(+)}{\theta_{S}}, \underset{(-)}{\theta_{S E}}, \underset{(+)}{m p k_{S}}\right), \quad r_{S E, t}=\Theta_{S E, t}\left(\underset{(+)}{z}, \underset{(-)}{\theta_{S}}, \underset{(+)}{\theta_{S E}}, \underset{(-)}{m p k_{S}}\right)
$$

Lower capital market tightness $\theta_{S E, t}$ puts upward pressure on $w_{S, t}$ since the self-employment option becomes a more accessible employment alternative. Also, as I discuss in detail in the results section below, $w_{S, t}$ and $r_{S E, t}$ are more sensitive to fluctuations in $\theta_{S E, t}$ in economies with higher steady-state self-employment (or equivalently, lower $\theta_{S E}$ ).

see how changes in $\theta_{S E, t}$ due to $v_{S E, t}$, holding everything else constant, would affect each of the prices. 


\subsection{Government, Total Output, and Resource Constraint}

The government levies lump-sum taxes to finance unemployment benefits, so the government budget constraint is

$$
T_{t}=b u_{t}
$$

Total output $y_{t}$ is given by the sum of output from salaried firms, $y_{S, t}$, and output from the self-employed, $y_{S E, t}$ :

$$
y_{t}=y_{S, t}+y_{S E, t}
$$

In the model, $y_{t}$ represents observed output in the data. Most countries follow United Nations guidelines and incorporate estimates of output from the informal sector, which most of the self-employed belong to, into their national income accounts (Quintin and Pratap, 2006; United Nations, 2008). ${ }^{26}$

As in most models with labor search frictions, the costs of posting vacancies and posting projects are resource costs and enter explicitly into the economy's resource constraint. Thus, the aggregate resource constraint is given by

$$
y_{t}=c_{t}+i_{t}+\psi_{S} v_{S, t}+\psi_{S E} \kappa\left(v_{S E, t}\right)
$$

where total output $y_{t}$ and investment $i_{t}$ were defined above.

\subsection{Competitive Equilibrium}

Definition (Competitive Equilibrium) Taking the set of exogenous processes $\left\{z_{t}, a_{S E, t}\right\}$ as given, the allocations $\left\{c_{t}, n_{S, t}, n_{S E, t}, \theta_{S, t}, \theta_{S E, t}, k_{S, t}, k_{S E, t}, \omega_{t}, u_{t}, T_{t}, y_{t}\right\}_{t=0}^{\infty}$ as well as prices $\left\{w_{S, t}, r_{S E, t}\right\}_{t=0}^{\infty}$ satisfy the law of motion for capital used in self-employment (3), the law of motion for self-employment (4), the definition of unemployment (6), the self-employed's demand for self-employed capital (7), the law of motion for salaried employment (10), the salaried firms' salaried job creation condition (13), the Euler equation for capital (14), the salaried firms' capital supply of self-employed capital (15), the Nash wage and the Nash rental rate equations (23) and (24), the government budget constraint (26), the definition of total output (27), and the economy's resource constraint (28).

\footnotetext{
${ }^{26}$ I focus on urban employment and therefore abstract from economic activity in agriculture, even though developing countries have large self-employment shares in the sector. Strictly speaking, total output should include an additional term that captures the contribution of the agricultural sector to total production. In my framework, this could be done by including a constant term in the definition of total output.
} 


\section{Calibration and Solution Method}

Given my interest in economies with sizeable self-employment shares, a natural choice for the calibration of the model is a developing country. I choose Mexico as a benchmark because its household and firm surveys give a detailed overview of self-employment in the labor market. Moreover, Bosch and Maloney (2008) have documented the cyclical dynamics of salaried employment and self-employment in Mexico, so their work is an excellent source for some of the parameter values and calibration targets used to simulate the model.

To analyze the dynamic behavior of the economy, I log-linearize the model around the non-stochastic steady state and compute a first-order approximation of the equilibrium conditions. I simulate the economy for 2100 periods, drop the first 100 periods, and use the Hodrick-Prescott (HP) filter with smoothing parameter 1600 to filter the simulated data, extract the cyclical component and compute the moments of interest. $^{27}$

\subsection{Functional Forms and Stochastic Processes}

Aggregate productivity $z_{t}$ and self-employment productivity $a_{S E, t}$ follow independent AR(1) processes:

$$
\ln z_{t}=\rho_{z} \ln z_{t-1}+\varepsilon_{t}^{z}
$$

and

$$
\ln a_{S E, t}=\rho_{S E} \ln a_{S E, t-1}+\varepsilon_{t}^{S E}
$$

where $\varepsilon_{t}^{z} \stackrel{i i d}{\sim} N\left(0, \sigma_{z}\right), \rho_{z}<1, \varepsilon_{t}^{S E} \stackrel{i i d}{\sim} N\left(0, \sigma_{S E}\right)$, and $\rho_{S E}<1$. Salaried output is Cobb-Douglas and given by $y_{S, t}=z_{t} a_{S}\left(n_{S, t}\right)^{1-\alpha_{S}}\left(\omega_{t} k_{S, t}\right)^{\alpha_{S}}, 0<\alpha_{S}<1$. Recall that $a_{S}$ is a time-invariant parameter in the salaried sector and not a shock. The cost of posting projects is given by $\kappa\left(v_{S E, t}\right)=\left(v_{S E, t}\right)^{\eta_{S E}}$ with $\eta_{S E}>1$. The matching function for salaried employment is constant-returns-to-scale, so $m_{S}\left(u_{t}, v_{S, t}\right)=$ $M_{S} u_{t}^{\xi} v_{S, t}^{1-\xi}, 0<\xi<1$, where $M_{S}$ is the salaried matching efficiency parameter, $u_{t}$ is unemployment, and $v_{S, t}$ denotes salaried vacancies. Then the salaried job-finding rate is $p\left(\theta_{S, t}\right)=\frac{m_{S}\left(u_{t}, v_{S, t}\right)}{u_{t}}=M_{S} v_{S, t}^{1-\xi} u_{t}^{\xi-1}=$ $M_{S} \theta_{S, t}^{1-\xi}$, and the salaried job-filling rate is given by $q\left(\theta_{S, t}\right)=\frac{m_{S}\left(u_{t}, v_{S, t}\right)}{v_{S, t}}=M_{S} u_{t}^{\xi} v_{S, t}^{-\xi}=M_{S} \theta_{S, t}^{-\xi}$. The matching function in the capital market is also Cobb-Douglas, so that $m_{S E}\left(\left(1-\omega_{t}\right) k_{S, t}, v_{S E, t}\right)=M_{S E}((1-$ $\left.\left.\omega_{t}\right) k_{S, t}\right)^{\xi_{S E}}\left(v_{S E, t}\right)^{1-\xi_{S E}}, 0<\xi_{S E}<1$. The probability of finding a self-employed individual from the point of view of the firm is $q\left(\theta_{S E, t}\right)=\frac{m_{S E}\left(\left(1-\omega_{t}\right) k_{S, t}, v_{S E, t}\right)}{\left(1-\omega_{t}\right) k_{S, t}}=M_{S E}\left(\left(1-\omega_{t}\right) k_{S, t}\right)^{\xi_{S E}-1}\left(v_{S E, t}\right)^{1-\xi_{S E}}=$

\footnotetext{
${ }^{27}$ I use Dynare for all dynamic simulations. Using higher-order approximations does not change the main conclusions of the paper.
} 
$M_{S E} \theta_{S E, t}^{1-\xi_{S E}}$ while the probability of finding a capital supplier is $p\left(\theta_{S E, t}\right)=\frac{m_{S E}\left(\left(1-\omega_{t}\right) k_{S, t}, v_{S E, t}\right)}{v_{S E, t}}=M_{S E}((1-$ $\left.\left.\omega_{t}\right) k_{S, t}\right)^{\xi_{S E}}\left(v_{S E, t}\right)^{-\xi_{S E}}=M_{S E} \theta_{S E, t}^{-\xi_{S E}}$

\subsection{Parametrization and Calibration Targets}

I borrow a number of parameter values that have been used in related studies and calibrate the remaining parameters using specific targets for Mexico. Table 3 below presents the parameter values adopted from existing literature. Table 4 shows the parameters whose values are obtained by imposing particular calibration targets from the data and solving for the model's non-stochastic steady state.

Parameters Taken from Existing Literature The time period in the model is one quarter, so I set the discount factor $\beta$ to 0.98 , consistent with common values assumed for developing countries. The capital share in the firm's production function is set to $\alpha_{S}=0.30$, a common value in DSGE models. The depreciation rate of capital is set to 0.02. Bosch and Maloney (2007) compute transition probabilities between employment states for Mexico using quarterly data from the National Survey on Urban Employment (Encuesta Nacional de Empleo Urbano, or ENEU) for years 1987 through 2002. They find that separation rates for informal salaried workers are at least twice as high as those for formal salaried workers. Self-employment separation rates are closer to those of formal workers.

Table 3: Parametrization: Benchmark Economy

\begin{tabular}{ccll}
\hline \hline Parameter & Value & Parameter Description & Parameter Source \\
\hline$\alpha_{S}$ & 0.30 & Salaried Capital Share & DSGE Lit. \\
$a_{S}$ & 0.60 & Institutional Quality & Benchmark Assumption \\
$b$ & 0 & Unemployment Insurance & No Unempl. Benefits \\
$\beta$ & 0.98 & Discount Factor & DSGE Lit. \\
$\delta$ & 0.02 & Capital Depreciation Rate & DSGE Lit. \\
$\delta^{S}$ & 0.05 & Salaried Separation Rate & Bosch, Maloney (2007) \\
$\delta^{S E}$ & 0.03 & SE Separation Rate & Bosch, Maloney (2007) \\
$\nu_{S}$ & 0.50 & Salaried Bargaining Power & Search Lit. \\
$\nu_{S E}$ & 0.50 & SE Bargaining Power & Search Lit. \\
$\rho_{z}$ & 0.90 & Autocorrelation of TFP & DSGE Lit. \\
$\xi$ & 0.50 & Matching Elasticity, Labor & Search Lit. \\
$\xi_{S E}$ & 0.50 & Matching Elasticity, Capital & Search Lit. \\
\hline
\end{tabular}

Since I have a single type of salaried employment, I set the salaried separation rate to be a weighted average of the two salaried separation rates, where the weights are given by each salaried type's contribution to total salaried employment. This implies that $\delta^{S E}<\delta^{S}$. The conclusions in the paper remain 
intact if I make a distinction between formal and informal salaried employment in the model. I set the persistence parameter for $z_{t}$ to 0.90 , in line with the DSGE literature. The elasticities of the matching functions and the bargaining power parameters are set to $\xi=\xi_{S E}=0.50$ and $\nu_{S}=\nu_{S E}=0.50$, respectively, consistent with the labor search literature (and to maintain as much symmetry as possible). $a_{S}$ is a free parameter that I vary to generate changes in steady-state self-employment in the model. I fix its value to 0.60 in the benchmark economy. Variations in $a_{S}$ allow me to generate sizeable changes in steady-state self-employment, ranging from 6 percent to 79 percent of the labor force. The benchmark value for $a_{S}$ allows me to obtain these changes in steady-state self-employment while keeping the share of capital used in salaried production bounded below one. ${ }^{28}$ As I discuss below, I treat this parameter as a proxy for institutional quality.

Calibrated Parameters The remaining parameters are jointly calibrated by solving for the nonstochastic steady state of the model and imposing specific data targets. The calibrated parameters are: $\eta_{S E}, M_{S}, M_{S E}, \psi_{S}, \psi_{S E}, \rho_{S E}, \sigma_{S E}$, and $\sigma_{z}$. Recall that $\eta_{S E}$ governs the curvature of the cost of posting self-employment projects and therefore the probability of entry into self-employment through the household's project posting condition. I calibrate $\eta_{S E}$ to match the volatility of the transition probability from unemployment to self-employment reported in Bosch and Maloney (2008). Given my benchmark assumption for $a_{S}$, I choose the matching scale parameters $M_{j}$, for $j=S, S E$ to match the average shares of salaried employment and self-employment in the total labor force for Mexico from 1987 to 2002, which are obtained from the ENEU and the ILO. The sectoral productivity shock to self-employment $a_{S E, t}$ aims to capture the added volatility and riskiness of the self-employment sector. Given the structure of self-employment entry in the model, I calibrate the persistence of the self-employment productivity shock to match the cyclical correlation between output and the transition rate from unemployment to self-employment documented in Bosch and Maloney (2008). I set the vacancy posting cost for salaried positions $\psi_{S}$ to be 3.5 percent of wages, as documented in Levy (2007). The target for the posting project cost parameter $\psi_{S E}$ is taken from McKenzie and Woodruff (2006), who document evidence on startup costs among microenterprises for different sectors using Mexico's microenterprise survey (Encuesta Nacional de Micronegocios, or ENAMIN). The target for $\psi_{S E}$ represents three months of wages, which is a lower-bound estimate for micro firms in construction and personal services.

\footnotetext{
${ }^{28}$ Even though the benchmark value for $a_{S}$ may suggest that productivity in the salaried sector is lower than productivity in self-employment, computing labor productivity for the benchmark economy reveals that labor productivity is indeed higher in the salaried sector relative to the self-employment sector, as it should be.
} 
Table 4: Calibrated Parameters and Targets: Benchmark Economy

\begin{tabular}{ccll}
\hline \hline Parameter & Value & Parameter Description & Target \\
\hline$\eta_{S E}$ & 1.11 & Curvature, Project Postings & $\sigma_{p^{u}\left(\theta_{S E, t}\right)}=9.4$ \\
$M_{S}$ & 0.198 & Salaried Matching Efficiency & $n_{S}=0.72$ \\
$M_{S E}$ & 0.028 & SE Matching Efficiency & $n_{S E}=0.23$ \\
$\psi_{S}$ & 0.027 & Formal Vacancy Cost & 3.5 percent of wages \\
$\psi_{S E}$ & 0.759 & Project Posting Cost & 3 months of wages \\
$\rho_{S E}$ & 0.67 & Autocorr. SE Prod. & $\rho_{p^{u}\left(\theta_{S E, t}\right), y_{t}}=-0.43$ \\
$\sigma_{S E}$ & 0.025 & SD SE Productivity Shock & $\rho_{y_{t}, y_{t-1}}=0.72$ \\
$\sigma_{z}$ & 0.0155 & SD Aggregate TFP Shock & $\sigma_{y}=2.17$ \\
\hline
\end{tabular}

I calibrate $\sigma_{S E}$ to match the autocorrelation of output in the data. ${ }^{29}$ Note that this also generates a volatility differential between self-employment earnings and salaried employment earnings, which is in line with the evidence on the higher earnings volatility in self-employment (see Hamilton, 2000, for the U.S., and Bargain and Kwenda, 2010, for Brazil and Mexico). ${ }^{30}$ Finally, the standard deviation of TFP is chosen to match the standard deviation of output for Mexico as reported in Lama and Urrutia (2012).

Table 5 shows the moments generated by the benchmark calibration of the model. It also shows three additional moments that are not targeted, mainly the cyclical correlation between self-employment and output, the cyclical correlation between salaried employment and output, and the correlation between unemployment and output for Mexico. The third column shows the same moments generated by an alternative version of the benchmark model where there are no capital search frictions, and transitions from unemployment into self-employment depend solely on a fixed probability of becoming self-employed. ${ }^{31}$

The benchmark model is able to explain the negative correlations between output and self-employment and unemployment observed in the data. In contrast, a model with an exogenous transition rate into selfemployment and no capital search frictions cannot replicate the contemporaneous cyclical correlation

\footnotetext{
${ }^{29}$ While I use the cyclical correlation between the transition rate from unemployment to self-employment and output in the data to calibrate the persistence of the shock to self-employment productivity, the model still generates the countercyclical transition rate from unemployment into self-employment (and the countercyclicality of selfemployment) when I shut down the sectoral shock. The only reason I use this moment as a target is to avoid assigning arbitrary parameter values to the self-employment productivity process. Calibrating the process also allows me to have a more disciplined quantitative experiment.

${ }^{30}$ Since I make no distinction between formal and informal salaried workers in the model, the target for the cyclical correlation of entry into salaried employment and output is a weighted average of the cyclical correlations for the two employment states, where the weights are given by the respective shares of formal and informal salaried workers in total salaried employment.

${ }^{31}$ The latter can be interpreted as the probability of receiving an idea for a self-employment venture. This alternative version of the model assumes that (fixed) effort is the only input in self-employment.
} 
Table 5: Benchmark Economy vs. Model with Exogenous Transition Rate Into Self-Employment

\begin{tabular}{ccc}
\hline \hline Targeted Moments & Benchmark Model & Model with Exogenous SE Entry \\
\hline$n_{S}$ & 0.72 & 0.72 \\
$n_{S E}$ & 0.23 & 0.23 \\
$\rho_{p^{u}}\left(\theta_{S E, t}\right), y_{t}$ & $-\mathbf{0 . 4 2}$ & - \\
$\rho_{p\left(\theta_{S, t}, y_{t}\right.}$ & 0.67 & 0.67 \\
$\sigma_{p^{u}\left(\theta_{S E, t}\right)}$ & 9.4 & - \\
$\sigma_{y}$ & 2.18 & 2.18 \\
\hline Other Moments & & \\
\hline$\rho_{n_{S E, t}, y_{t}}$ & $\mathbf{- 0 . 5 6}$ & $\mathbf{0 . 1 2}$ \\
$\rho_{n_{S, t}, y_{t}}$ & 0.69 & 0.57 \\
$\rho_{u_{t}, y_{t}}$ & $\mathbf{- 0 . 6 5}$ & $\mathbf{- 0 . 4 9}$ \\
\hline
\end{tabular}

between self-employment and output observed in the data. ${ }^{32}$ This model also yields weaker cyclical correlations between salaried employment and output and unemployment and output, respectively. The results in Table 5 highlight the importance of endogenizing the transition rate into self-employment to capture the cyclical facts about self-employment as well as other cyclical features of the labor market.

\section{Simulation Results}

Changes in the steady-state share of self-employment across simulations are engineered by varying the salaried sector productivity parameter, $a_{S}$. I interpret changes in this parameter as differences in the quality of institutions, which have been shown to be important for cross-country differences in self-employment rates (see, for example, Loayza and Rigolini, 2011). ${ }^{33}$

\subsection{Steady State}

Figure 2 shows the steady-state relationship between self-employment and other model variables traced out by variations in the institutional quality parameter $a_{S}$, holding other model parameters fixed. The parameter $a_{S}$ is centered at 0.60 for the benchmark economy and varies between 0.54 and 0.63 to generate steady-state self-employment shares ranging from 6.6 percent of the labor force to 79 percent of the labor

\footnotetext{
${ }^{32}$ There are no plausible parameter values for the self-employment productivity process that yield the cyclicality of entry into self-employment (or the cyclicality of self-employment) in the model with exogenous entry into selfemployment.

${ }^{33}$ The correlation between $a_{S}$ in the model and the index of Law and Order from Political Risk Services is 0.55 and significant at the 1 percent level, while the correlation between $a_{S}$ and Rule of Law from the World Bank's Worldwide Governance Indicators is 0.63 and significant at the 1 percent level as well. The correlation between the self-employment share in the data and Law and Order (Rule of Law) is -0.62 (-0.68) and significant at the 1 percent level.
} 
force. ${ }^{34}$ First, note that an increase in $a_{S}$ causes a fall in steady-state self-employment by raising the marginal product of salaried labor and the marginal product of capital used in the salaried sector.

Figure 2: Model Steady State and Self-Employment (Share of Labor Force)
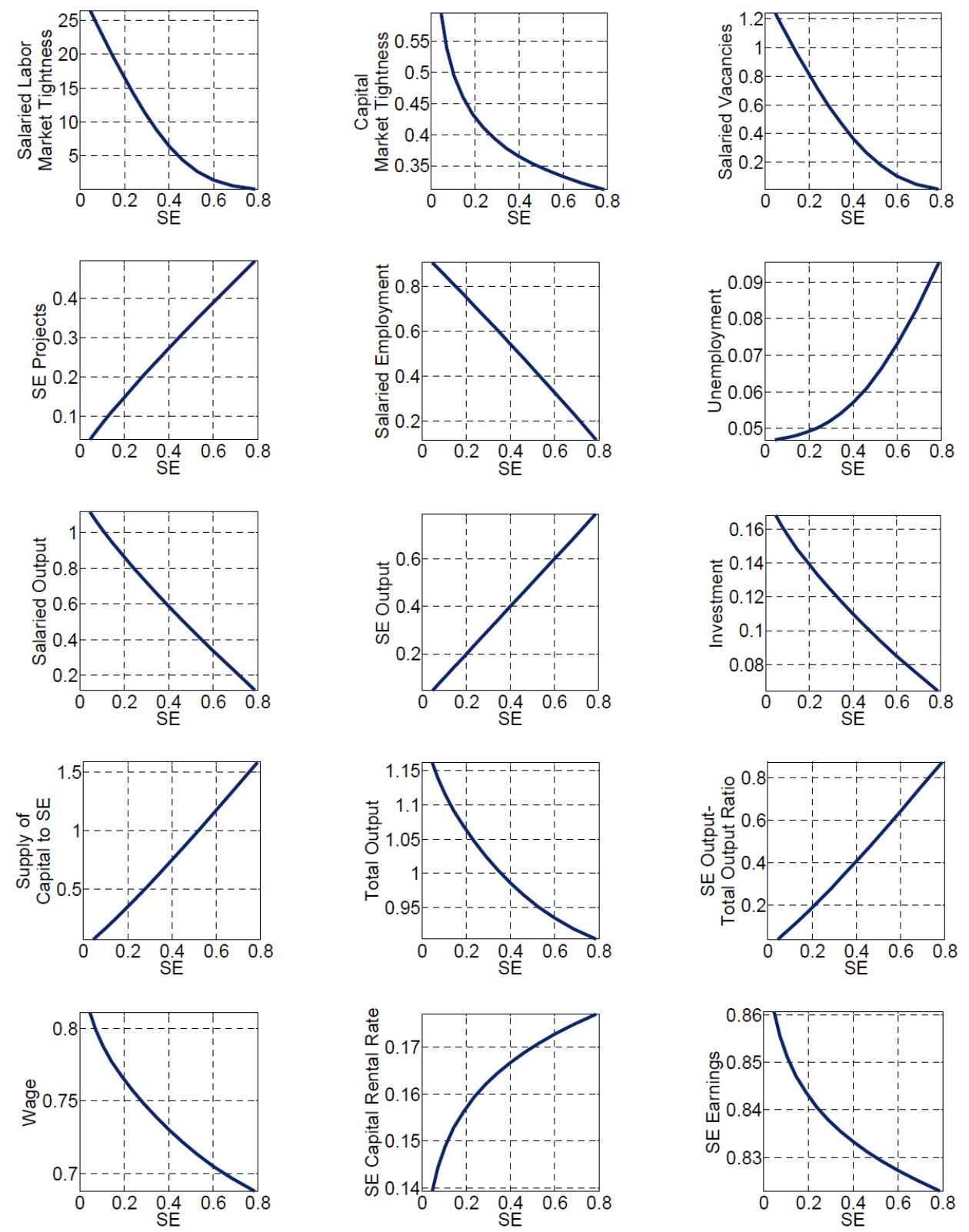

These changes in marginal products increase the value of posting salaried vacancies and decrease capital

\footnotetext{
${ }^{34}$ Given the response of steady-state unemployment to changes in $a_{S}$, this implies a range for self-employment of 7 percent to 87 percent of total employment (which is the variable plotted in Figure 1).
} 
supply to the self-employed, respectively. ${ }^{35}$ Thus, vacancies in salaried employment fall as the steady-state share of self-employment rises in the economy, as do steady-state salaried-firm capital and investment. The fall in vacancies and the increase in unemployment explain the fall in salaried labor market tightness for higher steady-state self-employment levels. Naturally, given the behavior of salaried vacancies, salaried employment and self-employment are negatively related. Since both physical capital and the share of the capital stock used in salaried production are higher in economies with less self-employment, salaried output and self-employment are negatively related.

The positive relationship between steady-state self-employment and unemployment suggests that selfemployment cannot fully absorb the individuals who move into unemployment when vacancies in the salaried sector fall. While the household has an incentive to post more self-employment projects when salaried labor market tightness is lower, the increase in project postings does not cause an increase in capital market tightness, because a lower $a_{S}$ reduces the share of capital devoted to production in the salaried sector, which implies an increase in the supply of capital to matching. The increase in capital supply is larger than the increase in capital demand, causing a decrease in capital market tightness. Output in the self-employment sector is positively related to self-employment, since production in the sector in the steady state depends solely on the share of self-employment in the economy. The share of self-employment output in total output is therefore increasing in self-employment. ${ }^{36}$

The model yields a negative relationship between total output and the share of self-employment, which is in line with the cross-country empirical evidence on the link between GDP and self-employment. Market conditions in each of the employment states are important determinants of the wage and the rental rate. In particular, recall that salaried sector wages are increasing in salaried labor market tightness and decreasing in capital market tightness. Plotting steady-state self-employment against the wage and the rental rate reveals that wages decline as self-employment rises, suggesting that the impact on wages from lower labor market tightness outweighs the impact from lower capital market tightness. If we consider the rental rate of capital, an increase in labor market tightness puts downward pressure on the rental rate because the probability of transitioning into salaried employment is higher. The opposite holds true for capital

\footnotetext{
${ }^{35}$ The marginal product of salaried employment would be lower even if increases in steady-state self-employment originated from changes in capital matching efficiency or other parameters that affect the share of self-employment in the economy. Intuitively, regardless of the parameter I use to change the share of self-employment in the model, economies with more self-employment use less capital in the salaried sector, which decreases the marginal product of labor for a given level of employment. Thus, the general conclusions I present do not depend on using $a_{S}$ to change the share of self-employment.

${ }^{36}$ The ratio for the benchmark economy is close to 0.20 . We can consider this as the share of output from informal enterprises, which excludes output from informal workers in formal firms but includes most of the output from self-employment, in total output. In Mexico, this ratio was 0.173 for years 2003 through 2006 (see http://wiego.org/informal-economy/statistical-picture).
} 
market tightness. However, similar to the case of wages, the effect of labor market tightness is stronger in steady state, which makes the rental rate rise with self-employment. Thus, wages and self-employment are negatively related while self-employment and the rental rate are positively related. This implies that the cost of renting capital is lower in economies with higher institutional quality $a_{S}$. In terms of understanding the cyclical dynamics reported below, the most relevant steady-state results are the negative relationship between self-employment and capital market tightness, the positive links between self-employment, project postings, and the supply of capital, and the negative connection between self-employment and salaried labor market tightness.

\subsection{Dynamic Response to a Negative Aggregate Productivity Shock}

I first describe the dynamic response of the model's variables to a negative aggregate productivity shock $z_{t}$ for the benchmark economy. I then discuss how cyclical dynamics differ across three economies with different steady-state self-employment levels, obtained by varying the salaried sector productivity parameter $a_{S}$. The shocks are the same across economies. I examine an economy with steady-state self-employment of 7.5 percent of total employment, which corresponds to the level in the United States; an economy with 23 percent self-employment, which corresponds to the level in the benchmark economy, Mexico; and an economy with 50 percent self-employment, which corresponds to the level in Colombia. These three choices are only meant to be illustrative. ${ }^{37}$ The following discussion refers to the results in Figures 3 through 5 .

Benchmark Economy On impact, the fall in aggregate TFP immediately lowers the marginal product of labor in salaried employment and the marginal product of capital used by salaried firms. Firms cut back on vacancies and investment. Since unemployment is predetermined in period $t$, salaried labor market tightness responds solely to changes in vacancies and falls, causing matching in the salaried sector to fall. This implies an upward jump in the probability of filling a salaried vacancy from the point of view of salaried firms.

\footnotetext{
${ }^{37}$ The only parameter that varies across economies is $a_{S}$. I do not claim that the model economies with 7.5 and 50 percent self-employment capture the U.S. and the Colombian economies, respectively.
} 
Figure 3: Impulse Response Functions to a Negative Aggregate Productivity Shock
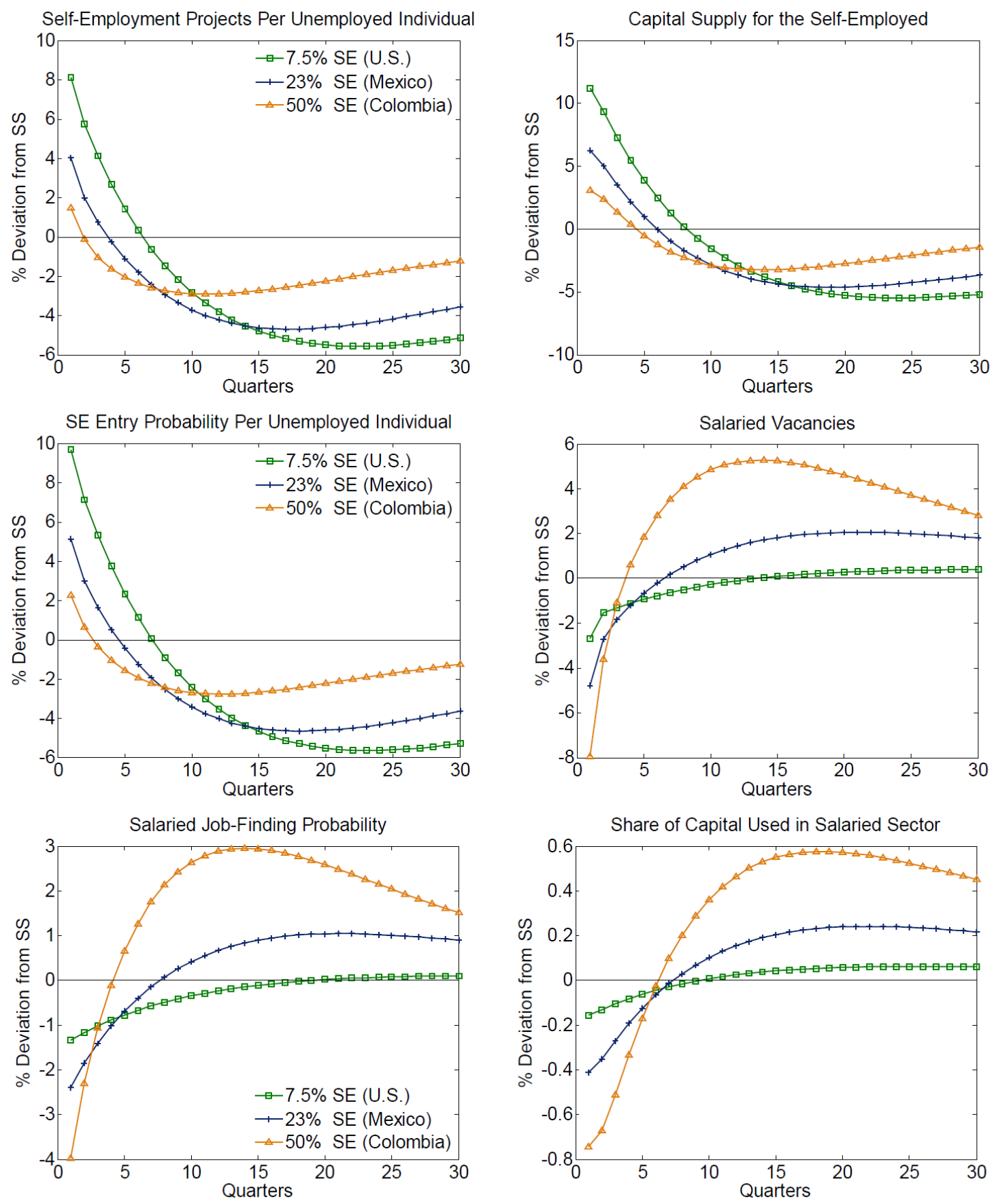

The fall in aggregate productivity pushes firms to decrease the share of capital used in salaried sector production, $\omega$. Since the capital stock is predetermined in $t$, a fall in the share of capital used by salaried firms implies that the supply of capital for matching, $(1-\omega) k_{S}$, increases on impact. As I describe below, 
Figure 4: Impulse Response Functions to a Negative Aggregate Productivity Shock (Continued)
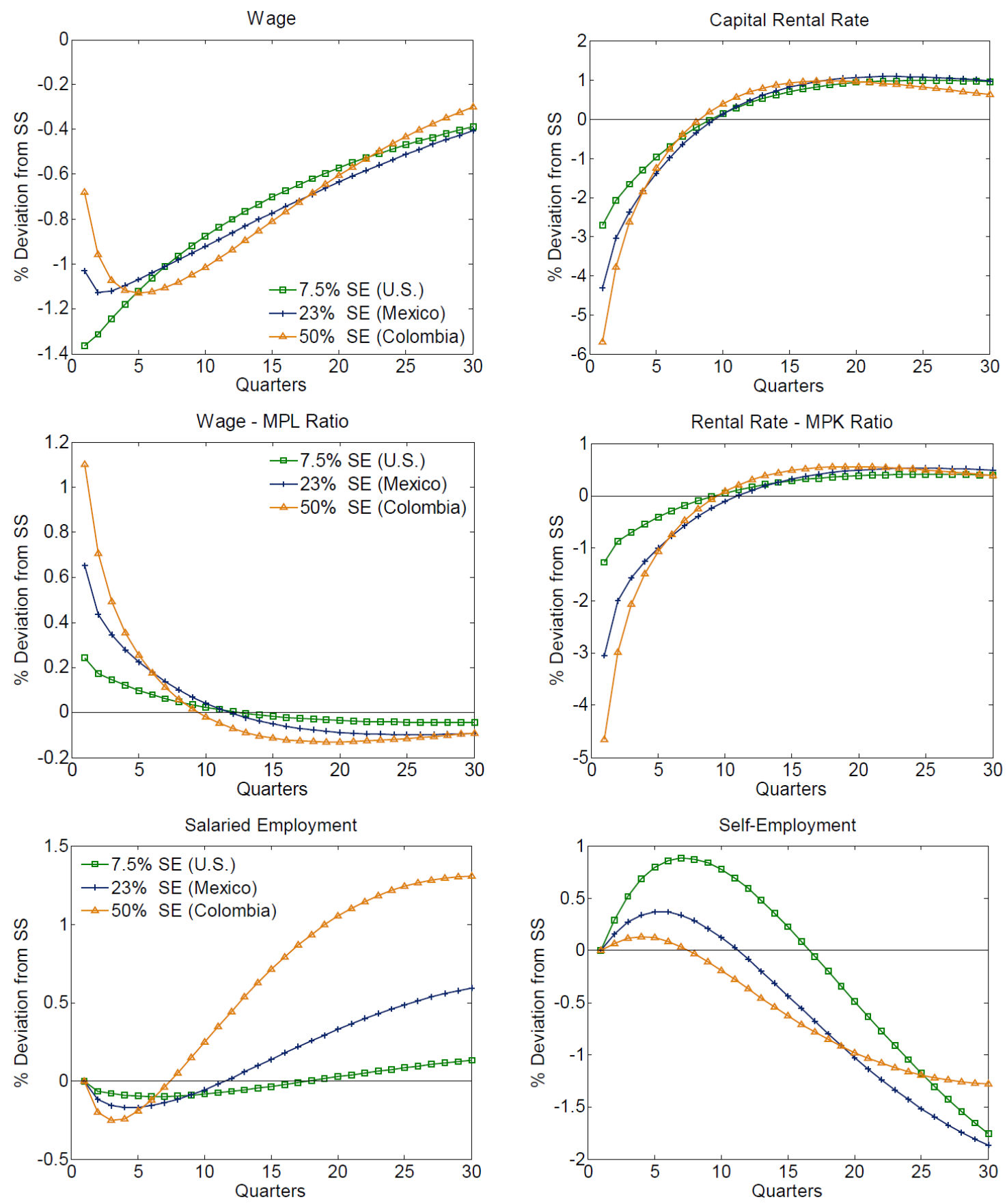

the rental rate on self-employment capital falls on impact. Households respond to the decline in both the probability of finding a salaried job and in the capital rental rate by posting more self-employment projects relative to the previous period. The increase in the supply of capital by salaried firms dominates 
Figure 5: Impulse Response Functions to a Negative Aggregate Productivity Shock (Continued 2)
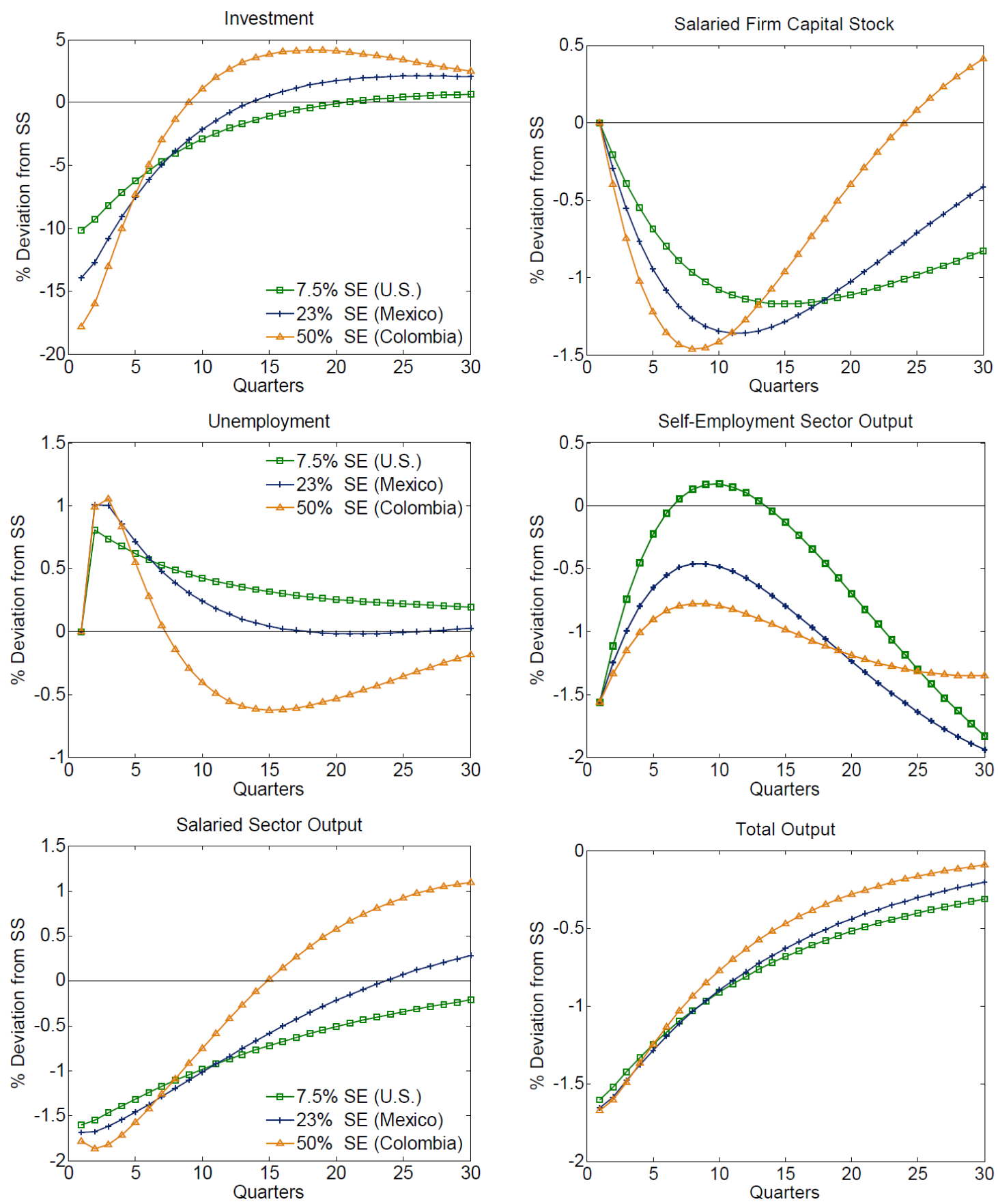

the increase in project postings, so that capital market tightness falls on impact. ${ }^{38}$ Recalling that $p\left(\theta_{S E}\right)$ is decreasing in capital market tightness, the fall in $\theta_{S E}$ translates into an increase in the probability of

\footnotetext{
${ }^{38}$ In principle, the impact response of capital market tightness is ambiguous since both the supply and the demand for self-employment capital have increased. For a reasonable calibration, the supply of capital always dominates.
} 
finding a capital supplier from the point of view of the household, and hence an increase in the probability of entering self-employment. ${ }^{39}$ Therefore, transition rates from unemployment into self-employment are countercyclical. Even though self-employment expands, output in the self-employment sector falls due to the fall in aggregate TFP. Since salaried output is also lower, this implies that total output in the economy falls on impact as well.

The initial responses of the wage and the rental rate are more subtle to analyze. First, note that a fall in capital market tightness raises the probability of becoming self-employed and puts upward pressure on wages. Second, a fall in salaried labor market tightness puts upward pressure on the rental rate, whereas the fall in capital market tightness has the opposite effect. In the end, the effect of salaried labor market tightness drives the behavior of wages, while the effect of capital market tightness dominates in explaining the behavior of the rental rate. Hence, both the wage and the rental rate fall on impact. This result is intuitive: for a given level of self-employment, conditions in salaried employment should exert more influence on wages than conditions in self-employment, even though the latter still affects the behavior of wages. As I discuss below, important differences emerge once we analyze economies with different steady-state self-employment levels since capital market tightness plays an increasingly important role in shaping the response of wages as the steady-state level of self-employment increases.

Due to labor matching frictions, the initial fall in vacancies leads to a persistent fall in salaried employment. Also, since investment falls on impact, the lower capital stock next period slows down the recovery of the marginal product of salaried labor, which negatively affects salaried employment in subsequent periods. This has a direct impact on the recovery of salaried employment and output in the aftermath of the shock. Despite the effect of capital on salaried employment, there is a large rebound in salaried vacancies (and salaried labor market tightness) in the period after the shock. To understand this, note that in the benchmark economy wages fall further in the period after the shock, and the self-employment outside option plays a key role in this result. The recovery in aggregate productivity (and hence the marginal product of capital) pushes salaried firms to use more capital in-house. This reduces the supply of capital to the self-employed, which exerts upward pressure on the self-employment capital rental rate. ${ }^{40}$ In response to the rise in the rental rate, households post fewer self-employment projects. The lower demand for capital in self-employment lowers the probability of entering self-employment and effectively reduces

\footnotetext{
${ }^{39}$ This holds whether we look at the total probability of entering self-employment, $p\left(\theta_{S E}\right)$, or the probability per unemployed individual, $v_{S E}^{u} p\left(\theta_{S E}\right)$. The latter is the appropriate variable to compare against the salaried job-finding probability.

${ }^{40}$ Note the tension between the rise in the marginal product of capital - which pushes firms to devote less capital to matching and hence increases $\omega$ - and the rise in the rental rate - which pushes firms to devote more capital to matching and hence decreases $\omega$. The first effect eventually dominates the second effect, which brings the share of capital used in salaried production back to steady state.
} 
the self-employment outside option by enough that wages fall further after the period of the shock. Since the marginal product of labor also starts to recover as aggregate productivity slowly rises back to steady state, the salaried firm's surplus from hiring workers increases, which further feeds the rise in salaried vacancies. Eventually, the downward pressure from the value of the self-employment option on wages winds down and is offset by rising labor market tightness, and wages begin their upward path back to steady state.

Absent the effect of endogenous movements in capital market tightness on salaried wages after the shock, real wages in the economy would simply fall on impact and start recovering in the subsequent period. This is a natural consequence of the fact that vacancies, labor market tightness, and the marginal product of labor all rise with the recovery of aggregate productivity, as in the standard labor search model. Hence, the dynamic response of the ease of entry into self-employment is critical to the speed of recovery of salaried employment and output, as the probability of becoming self-employed affects the recovery path of salaried wages. I show below that this mechanism becomes more relevant as self-employment in the economy increases.

Differences Across Economies on Impact The impulse response function for total output at the bottom of Figure 5 shows that economies with more steady-state self-employment recover faster from an adverse aggregate productivity shock. This is one of the main results of the paper. To understand this result, it proves useful to first see how the impact responses differ across economies.

Economies with more self-employment have a lower steady-state value of vacancies, which reflects the lower level of labor productivity in the salaried sector. ${ }^{41}$ Thus, when salaried firms in these economies face an adverse aggregate shock, the proportional downward adjustment in salaried vacancies will be larger, causing salaried labor market tightness to fall by more as well, as shown in Figure 3. The larger decrease in vacancies is accompanied by a larger fall in the share of capital used in production, $\omega$. The fall in investment is larger in economies with more steady-state self-employment, which is due both to the larger drop in vacancies - a larger fall in vacancies lowers the incentive to accumulate capital since salaried employment will be lower next period - and to the lower steady-state capital-output ratio in these economies. Even though $\omega$ falls by more in economies with more self-employment, the lower steady-state

\footnotetext{
${ }^{41}$ Once again, note that this is not an artifact of the way I obtain different levels of steady-state self-employment through changes in the salaried sector productivity parameter $a_{S}$. For example, if I change steady-state selfemployment by varying the capital matching efficiency parameter $M_{S E}$, the results are qualitatively the same: the value of salaried vacancies is lower in economies with more self-employment because labor productivity is lower. This last result is due to the allocation of capital in the economy: more capital allocated to the self-employed implies a lower marginal product of labor in the salaried sector because the amount of capital used by salaried firms is lower for a given level of salaried employment.
} 
capital stock in these economies implies that capital supply to the self-employed, given by $(1-\omega) k_{S}$, expands by less in the period of the shock. Hence, the increase in transitions into self-employment is smaller in economies with more steady-state self-employment due to the weaker surge in capital supply for matching. Lastly, note that the larger fall in total output in economies with more steady-state selfemployment is driven by the response of salaried sector output on impact, which drops by more due to the behavior of the share of capital used in the salaried sector, $\omega$.

Since the fall in salaried labor market tightness is larger in economies with higher self-employment shares, we would expect wages to fall by more as well, but this is not the case in the model. To understand this result, recall that steady-state salaried labor market tightness is decreasing in self-employment. This implies that, for a given deviation from steady-state, a fall in labor market tightness has less of an effect on wages in economies with more self-employment. Intuitively, relative to economies with less self-employment, the self-employment outside option plays a larger role in stabilizing wages since the steady-state supply of capital for self-employment is larger, implying a higher likelihood of entering the sector. Even if conditions in salaried employment change, they will have less of an effect on wages since self-employment plays a more prominent role in shaping labor market conditions in these economies. This unique feature of the model arises from the fact that capital market tightness, and therefore the probability of becoming self-employed, is endogenous and affects how wages respond to aggregate productivity shocks.

To make this argument more transparent, consider the terms involving self-employment from a loglinearized version of the salaried sector wage equation:

$$
\left[\begin{array}{c}
\frac{v_{S E}^{u} z a_{S} f_{\omega k_{S}}}{w_{S} \theta_{S E}}\left(\widehat{v}_{S E, t}^{u}+\widehat{z}_{t}+\widehat{m p}_{\omega k_{S, t}}-\widehat{\theta}_{S E, t}\right) \\
+\frac{\left(1-\delta^{S E}\right)[1-\beta(1-\delta)] M_{S E} v_{S E}^{u} \xi_{S E}}{w_{S} \theta_{S E}^{\xi_{S E}}}\left(\widehat{v}_{S E, t}^{u}-\widehat{\theta}_{S E, t}+\widehat{\lambda}_{t+1}^{h}-\widehat{\lambda}_{t}^{h}\right)
\end{array}\right]
$$

where hats refer to variables are variables expressed in log-deviations from steady state, $m p_{\omega k_{S, t}}$ is the marginal product of capital for salaried firms, and $\lambda_{t}^{h}$ is the marginal utility of consumption. There are several things to note. First, the combined impact of the deviation in capital market tightness $\widehat{\theta}_{S E, t}$ can be written as

$$
-\left[\frac{v_{S E}^{u} z a_{S} f_{\omega k_{S}}}{w_{S} \theta_{S E}}+\frac{\left(1-\delta^{S E}\right)[1-\beta(1-\delta)] M_{S E} v_{S E}^{u} \xi_{S E}}{w_{S} \theta_{S E}^{\xi_{S E}}}\right]
$$

which is larger in absolute value in the calibrated economies with more steady-state self-employment, mainly due to the lower steady-state value of salaried wages and capital market tightness. This makes intuitive sense: given that the self-employment sector is larger in these economies, any movements in capital market tightness will have a larger impact on salaried wages through variations in the self-employment 
outside option, and conditions in self-employment more generally. Since $\widehat{\theta}_{S E, t}$ has a negative impact on wages, this implies that a fall in capital market tightness will limit the fall in wages resulting from lower labor market tightness and a lower marginal product of salaried labor in the period of the shock. Put another way, the counteracting effect on wages due to the self-employment outside option is greater in economies with more steady-state self-employment, which implies that wages fall by less on impact. ${ }^{42} \mathrm{~A}$ similar claim holds for increases in project postings per unemployed individual $v_{S E, t}^{u}$ in response to the negative shock, since the weight on $\widehat{v}_{S E, t}^{u}$ in absolute value is the same as for $\widehat{\theta}_{S E, t}$. Again, this is intuitive since the larger presence of self-employment in the economy implies that changes in market conditions in self-employment exert more influence on salaried labor market conditions. Hence, a given change in individual project postings in economies with more steady-state self-employment will have a larger stabilizing influence on the response of salaried wages in the period of the shock, and will make wages more rigid on impact.

Analyzing numerically each of the components of the coefficient on $\widehat{\theta}_{S E, t}$ in (32) shows that the larger steady-state supply of capital to self-employment is key to explaining the greater influence of $\widehat{\theta}_{S E, t}$ in economies with more self-employment: the supply of capital ultimately determines how accessible the self-employment outside option is, even though the availability of self-employment capital also depends on project postings. ${ }^{43}$ The upshot is that wages will fall by less on impact in economies with more selfemployment: the larger steady-state supply of capital for matching effectively bolsters the self-employment outside option in the period of the downturn, which in turn reduces the impact response of wages to changes in aggregate economic conditions. This relative rigidity in wages causes vacancies to take a larger hit in the period of the shock in economies with more steady-state self-employment.

In contrast to the behavior of wages, the rental rate is more sensitive to changes in capital market conditions in economies with more steady-state self-employment. Going back to the rental rate equation, recall that a fall in salaried labor market tightness puts upward pressure on the rental rate since the probability of finding salaried employment is lower. This effect is weaker in economies with more selfemployment since conditions in salaried employment have less influence on self-employment, and on labor market conditions in general. Conversely, a fall in capital market tightness puts downward pressure on the rental rate, and this effect is stronger in economies with more self-employment due to the higher

\footnotetext{
${ }^{42}$ Note that this is the case even if capital market tightness falls by less on impact in economies with more self-employment.

${ }^{43}$ Using the definition of $\theta_{S E}$ and $v_{S E}^{u}$, we can write $\left(v_{S E}^{u} z a_{S} f_{\omega k_{S}}\right) /\left(\theta_{S E} w_{S}\right)$ as $\left((1-\omega) k_{S} z a_{S} f_{\omega k_{S}}\right) /\left(u w_{S}\right)$. While $a_{S}$ and the supply of capital $(1-\omega) k_{S}$ move in the opposite direction, the change in $(1-\omega) k_{S}$ dominates the change in $a_{S}$ such that $\left((1-\omega) k_{S} z a_{S} f_{\omega k_{S}}\right) /\left(u w_{S}\right)$ increases with the share of self-employment in the economy. What is key here is that the numerator rises by more than the denominator.
} 
steady-state supply of capital devoted to self-employment. ${ }^{44}$ As it turns out, the second effect dominates, so that the rental rate will fall by more in economies with more self-employment.

As I argue below, the response of salaried wages plays a key role in the recovery process, so a brief summary of the impact response of wages is in order. First, recall that steady-state salaried labor market tightness is lower in economies with more self-employment, which makes wages fall by less when vacancies (and therefore salaried labor market tightness) fall in response to the shock. Second, the steady-state supply of capital to the self-employed in these economies is higher, implying a higher steady-state entry probability into self-employment. Thus, a fall in capital market tightness arising from an adverse aggregate shock will put more upward pressure on wages in economies with more self-employment. Both effects make wages initially less responsive to shocks in economies with more self-employment, while the opposite is true for the rental rate. The intuition is clear: economies with more self-employment are associated with a more accessible outside option in self-employment, which in turn has more influence on salaried-sector wages in the economy and makes wages initially less responsive when an aggregate shock hits the economy.

Differences Across Economies After the Shock To understand how the economy's steady-state level of self-employment affects the recovery path of total output, consider how the hiring pattern in the salaried sector evolves differently across economies in the aftermath of the shock. We know that the marginal product of labor starts to recover after the shock since TFP slowly returns back to steady state. In fact, the recovery path of this variable is virtually identical across economies since all economies face the same shock. What differs, however, is the behavior of wages. Recall that wages fall less on impact in economies with more self-employment. By itself, this causes a larger initial drop in salaried employment and output, and would tend to slow down their recovery. However, as shown in Figure 4, wages in these economies also have a more pronounced U-shaped recovery and keep falling several periods after the shock. This last fact is crucial to explaining why these economies recover faster in the model. As I describe below, the self-employment outside option plays a central role in shaping the path of wages after the shock.

Intuitively, changes in the probability of becoming self-employed as aggregate productivity recovers effectively determine how accessible the self-employment outside option is in the periods following the shock. In particular, the likelihood of becoming self-employed falls back to steady state more quickly in economies with more self-employment, thereby making self-employment a less accessible employment option. This puts downward pressure on wages, so that wages fall even further in the aftermath of the

\footnotetext{
${ }^{44}$ The coefficient on $\widehat{\theta}_{S E, t}$ in the log-linearized rental rate equation is the same as the one in the log-linearized wage equation, but with a positive sign. Thus, a fall in $\theta_{S E, t}$ in response to a negative aggregate productivity shock tends to lower the rental rate, ceteris paribus.
} 
shock. In turn, the more persistent fall in wages promotes a more rapid recovery of salaried vacancies, which leads to a faster recovery of salaried employment, investment and output.

The mechanism works as follows: first, steady-state capital market tightness is lower in economies with more steady-state self-employment, which implies a smaller rise in the probability of self-employment entry on impact. Second, since the pace of recovery in the marginal product of capital due to TFP is similar across economies, the share of capital used in salaried production recovers at a faster pace in economies with more self-employment since the former experienced a larger initial fall in these economies. This reduces the amount of capital devoted to matching with the self-employed by more, which in turn causes a faster recovery in the rental rate in the periods subsequent to the shock since the rental rate is more sensitive to changes in the supply of capital in these economies. The faster recovery in the rental rate in economies with more self-employment after the period of the shock sharply reduces the benefit from posting self-employment projects. Moreover, the larger collapse in salaried vacancy postings from the period of the shock translates into a larger increase in unemployment. Combining these last two facts, we see that self-employment project postings per unemployed individual fall back to steady state earlier in economies with more self-employment as the shock subsides. The larger contraction in capital supply reduces the availability of self-employment capital, and hence the probability of entry into self-employment falls back more quickly after the shock in economies with more self-employment. In simple terms, the self-employment outside option deteriorates faster in the aftermath of the shock in these economies.

As the possibility of becoming self-employed becomes less and less likely - which happens much earlier in economies with more self-employment as the availability of capital for self-employment falls more rapidly - the drop in the self-employment outside option puts continued downward pressure on wages in these economies. Thus, wages continue to fall for several periods after the shock, which creates a larger surplus from posting salaried vacancies. Salaried labor market tightness also starts to return to steady state in the period after the shock, which tends to raise wages. Eventually, the downward pressure arising from the lower availability of self-employment capital winds down, and the rise in salaried vacancies allows wages to begin their recovery back to steady state. What is important is that wages fall further after the shock in economies with more steady-state self-employment, even though wages are initially more rigid. Since the marginal product of labor begins its recovery immediately after the period of the shock as TFP recovers, this creates a larger difference between the marginal product of salaried labor and the wage - a larger contemporaneous value from hiring workers - which bolsters a faster recovery in vacancy postings in subsequent periods. ${ }^{45}$ In turn, the faster recovery of vacancies and employment in the salaried

\footnotetext{
${ }^{45}$ To make this argument clear, consider the ratio of the wage to the marginal product of salaried employment, shown in Figure 4. On impact, this ratio is greater in economies with more self-employment exactly because wages
} 
sector leads to a faster surge in investment in economies with higher steady-state self-employment shares. Finally, a faster recovery in salaried employment and investment bolster the recovery in salaried output, which in turn leads to a faster recovery in total output.

The Importance of Endogenous Transition Rates into Self-Employment The existence of selfemployment by itself is not sufficient to explain faster output recoveries in economies with higher steadystate self-employment. The evolution of the value of the self-employment outside option in response to shocks is critical to explaining why total output recovers faster in economies with more self-employment. A model with an exogenous transition rate into self-employment and no capital search frictions would not be able to explain the observed stylized fact in the data. ${ }^{46}$ Furthermore, the wage channel - whereby the dynamic behavior of the ease of entry into self-employment affects the self-employment outside option and hence the recovery path of wages after a negative shock - would not be present in such a model. Hence, an alternative model with a fixed transition probability into self-employment cannot explain why output would recover faster in economies with more self-employment. The contributions of this paper are therefore twofold: I offer a tractable framework that replicates the cyclicality of self-employment and the transition rate into self-employment from unemployment in the data, and I propose a plausible channel through which differences in the composition of employment across economies may have important consequences for the pace of economic recoveries.

\subsection{Model and Data Comparison}

To determine whether the model can yield reasonable predictions about the relationship between selfemployment and business cycle persistence, I check whether it can capture the empirical relationship initially shown in Figure 1.

To compare the prediction of the model against the relationship in the data, I take the simulated series for quarterly output and create an unfiltered annual output series in levels. I then log the series and extract the cyclical component of the annual series using the HP filter with smoothing parameter 100, as I did with the data. Finally, I compute the first-order autocorrelation of the cyclical output series for different economies by varying the parameter $a_{S}$ to change the steady-state level of self-employment. I then plot a second-order polynomial fit for the data, the data points for all the countries in the sample,

fail to fall as much as in economies with less self-employment. The persistent fall in wages induced by the evolution of the self-employment outside option pushes the ratio of the wage to the marginal product of labor down by a larger proportion in subsequent periods. This drives the larger surge in salaried vacancies.

${ }^{46}$ In this alternative model, salaried employment, investment, salaried output, and total output recover more slowly in economies with higher steady-state self-employment. 
Figure 6: Output Persistence and Self-Employment Rates: Data and Model Comparison

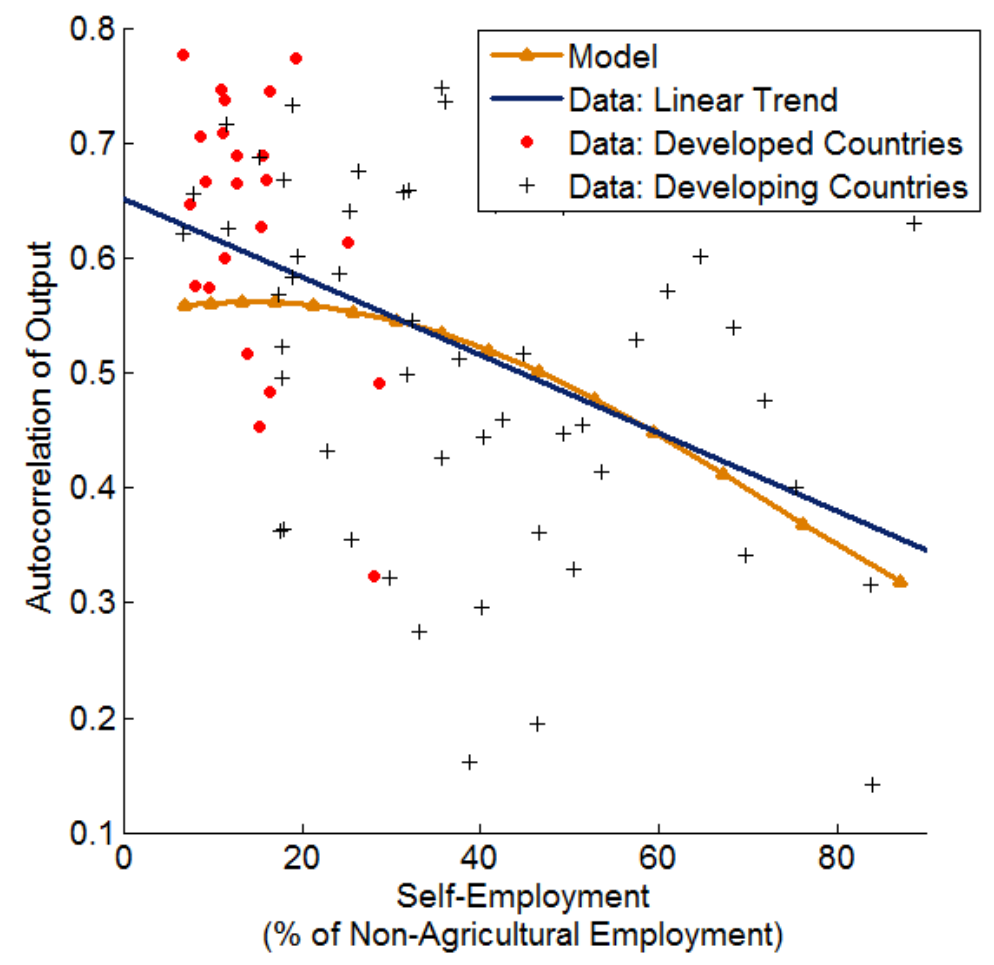

and the relationship generated by the model. Figure 6 shows that the model can capture the change in the autocorrelation of output for countries with high shares of self-employment reasonably well.

As a simple exercise, I regress the autocorrelation of output in the data, $A C(y)_{\text {data }}$ on the autocorrelation of output computed from the simulated series, $A C(y)_{\text {simulated }}{ }^{47}$ This yields:

$$
A C(y)_{\text {data }}=\underset{(0.199)}{-0.273}+\underset{(0.376)}{1.602} A C(y)_{\text {simulated }}
$$

where standard errors are shown in parentheses. The R-squared of the regression is 0.17 , implying that the model can explain 17 percent of the variation in the autocorrelation of cyclical output.

The model's ability to replicate the negative relationship between output persistence and self-employment rates in the data depends on the response of the variability of self-employment output to changes in the share of self-employment in the economy. As I briefly discuss below, the presence of the self-

\footnotetext{
${ }^{47}$ The idea for this experiment is borrowed directly from Moscoso Boedo and Mukoyama (2012). Using the model, I target the share of self-employment (as a percent of employment) for each country in Figure 1 (for a total of 83 countries). Then, for each self-employment share, I compute the autocorrelation of cyclical output using the simulated series, which yields $A C(y)_{\text {simulated }}$.
} 
employment productivity shock plays an important role in capturing the quantitative relationship between self-employment and output persistence.

In a version of the model without a self-employment productivity shock, the increase in the volatility of salaried output when self-employment increases would be offset by the decrease in the volatility of self-employment output as the sectoral output weights shift and raise the share of self-employment output in total output. ${ }^{48}$ The change in employment composition would merely change the composition of the volatility of total output without changing its level. This, in turn, would result in virtually no change in the persistence of output in the economy as the share of self-employment increases. Having a sectoral productivity shock in self-employment effectively reduces the sensitivity of self-employment output volatility to steady-state changes in the composition of employment. Intuitively, this is the case since the added variability from the sectoral shock dilutes the effect of changes in the volatility of self-employment on the variability of output in self-employment. ${ }^{49}$ Including a sectoral productivity shock to self-employment output substantially improves the model's ability to reproduce the empirical link between output persistence and self-employment, and also allows the model to capture additional qualitative stylized facts about the volatility of self-employment earnings, and the volatility of output across economies.

The inclusion of a sectoral shock in the self-employment sector can be justified on three grounds. First, this sector is well-known to face higher risk and higher volatility (Maloney, Cunningham, and Bosch, 2004). One way to capture this is to include a sectoral shock. Second, shutting down the sectoral shock generates similar volatilities in self-employment earnings and salaried labor earnings. This fact is inconsistent with the empirical evidence for various countries, which documents that self-employment earnings are more volatile than wage earnings (Hamilton, 2000; Bargain and Kwenda, 2010; Narita, 2010). In the simulations, I can capture this last stylized fact with the self-employment productivity shock $a_{S E, t}$. Finally, as I discuss below, if the shock hitting the economy originates in the self-employment sector, the model can deliver episodes of procyclical self-employment, which Fiess et al. (2010) have documented for particular time periods in certain Latin American countries. The inclusion of this shock allows me to test this fact in the data.

Even though I highlighted the model's quantitative success in replicating Figure 1, the main conclusion to draw from this exercise is that the model can capture the negative relationship between self-employment

\footnotetext{
${ }^{48}$ The covariance term between salaried output and self-employment output plays a minor role in determining changes in the variance of total output.

${ }^{49}$ This holds even though the volatility of self-employment changes with the variance of the sectoral shock. Note that increasing the volatility of the sectoral shock beyond the benchmark value would generate a stronger negative relationship between output persistence and the share of self-employment, even though the volatility of self-employment output is decreasing in the share of self-employment.
} 
and output persistence in a qualitative fashion. ${ }^{50}$ I take this to be an important indicator that the model of self-employment I propose is heading in the right direction.

\subsection{Additional Comments}

Total Factor Productivity Differences Recall that production in the salaried sector is given by $y_{S, t}=z_{t} a_{S} f\left(n_{S, t}, \omega_{t} k_{S, t}\right)=z_{t} a_{S}\left(n_{S, t}\right)^{1-\alpha_{S}}\left(\omega_{t} k_{S, t}\right)^{\alpha_{S}}, 0<\alpha_{S}<1$, where recall that $a_{S}$ is a proxy for institutional quality and $z_{t}$ is exogenous aggregate productivity. Naturally, economies can differ in total factor productivity (TFP) because of differences in $a_{S}$, which I consider exogenous. Following Lama and Urrutia (2012), we can rewrite $y_{S, t}$ as

$$
y_{S, t}=\overbrace{\underbrace{z_{t} a_{S}}_{\text {Exog. TFP } \quad \text { Endog. TFP }} \underbrace{\omega_{t}^{\alpha_{S}}}}^{\text {Measured } T F P_{t}}\left(n_{S, t}\right)^{1-\alpha_{S}}\left(k_{S, t}\right)^{\alpha_{S}}
$$

and hence decompose measured $T F P_{t}$ into an exogenous component, $z_{t} a_{S}$, and an endogenous component, $\omega_{t}^{\alpha_{S}}$. I can then compute steady-state differences in measured and endogenous TFP across economies. ${ }^{51}$

The simulations under the benchmark calibration show that measured TFP in an economy with 7 percent self-employment - equivalent to a country like the United States - is only 5 percent higher than in an economy with 23 percent self-employment, 16 percent higher than in an economy with 50 percent self-employment, and 57 percent higher than in an economy with 87 percent self-employment (the upper bound for the country sample in Figure 1). Similarly, endogenous TFP in an economy with 7 percent selfemployment is only 1.5 percent higher than in an economy with 23 percent self-employment, and 6 percent higher than in an economy with 50 percent self-employment. These results suggest that the allocation of capital across sectors in each economy accounts for a small share of the differences in measured TFP across economies.

The Response to a Positive Shock to Self-Employment Productivity The model can capture the countercylicality of self-employment and self-employment entry in the data. Using data from four

\footnotetext{
${ }^{50}$ Clearly, the polynomial fit (or a simple linear fit of the data) will change slightly if the countries with the highest shares of self-employment from the sample (70 percent or more) or some of the apparent outliers are excluded. However, the negative link between self-employment and cyclical output persistence would still hold despite changes in the country sample.

${ }^{51}$ For some related literature on cross-country differences in productivity, see Hsieh and Klenow (2009), Bartelsman, Haltiwanger, and Scarpetta (2013), Buera, Kaboski, and Shin (2011), among others. For a recent study on capital misallocation and institutions in Africa, see Kalemli-Ozcan and Sorensen (2012). Also, see Hopenhayn (2012), who proposes a simple mapping between distortions and aggregate productivity and finds much smaller effects on TFP from these distortions, in contrast to the existing literature.
} 
Latin American countries, Fiess et al. (2010) document particular episodes where self-employment is procyclical in these countries. They argue that the source of shocks may be important in determining whether self-employment expands or contracts in response to shocks to the economy. The inclusion of a sectoral productivity shock in self-employment allows me test this claim in the model. Both total output and self-employment expand in response to to a positive productivity shock in the self-employment sector. Intuitively, the shock increases the value of devoting resources to the self-employment sector, thereby causing a reallocation of accumulated capital in the salaried sector towards the self-employment sector and generating increased entry into self-employment. The contraction in capital used by salaried firms reduces vacancy postings in the salaried sector, but the increase in the supply of self-employment capital causes wages in the salaried sector to expand. Despite the higher value of supplying capital to the sector, investment falls. The expansion in self-employment output due to higher entry into the sector more than offsets the contraction in salaried output, leading to an expansion in total output. Thus, the model is able to both capture the evidence in Fiess et al. (2010) and generate the countercyclical behavior of self-employment documented in Loayza and Rigolini (2011).

Endogenous Separations in Self-Employment Bosch and Maloney (2008) document that separations from self-employment are strongly countercyclical. Would the model be able to generate the cyclicality of the separation rate in self-employment if separations are endogenous? Relatedly, would the main results in the paper be robust to the inclusion of endogenous separations in self-employment? The benchmark model shows that salaried firms will respond to a negative TFP shock by using less capital in production and devoting more capital to the self-employment sector. This takes place despite the fact that the shock affects both sectors. With endogenous separations, salaried firms have an additional margin of adjustment and can decide to destroy less capital relationships since having capital in the selfemployment sector acts as an additional source of income during bad times. If we assume that both old and new matches in self-employment start with the same idiosyncratic productivity each period, the threshold idiosyncratic productivity value that determines destruction in the sector can either rise or fall in response to a negative aggregate productivity shock. Thus, it is not clear whether separations would be countercyclical.

Assuming that new self-employment matches always start with higher productivity than existing matches would push salaried firms to destroy old matches in response to an adverse aggregate shock, and reallocate that capital to new matches that start with the highest productivity. ${ }^{52}$ This would not

\footnotetext{
${ }^{52}$ For a setup that uses this assumption in a model with two types of salaried employment, see Bosch and Esteban-Pretel (2006).
} 
only yield countercyclical separations in self-employment, as in the data, but would also allow for a net expansion of self-employment during recessions. More importantly, the mechanism through which differences in the share of self-employment affect the speed of recoveries - mainly, how the ease of self-employment entry affects the dynamic path of salaried wages in the aftermath of an aggregate shock - would not change relative to the benchmark economy. For example, as aggregate productivity slowly recovers after a negative shock, the separation rate from self-employment would begin to fall back to steady-state, and salaried firms would start to use more capital in-house. The fall in the amount of capital supplied to the self-employed would reduce the self-employment outside option, thereby putting downward pressure on salaried wages. This would generate similar qualitative dynamics relative to the benchmark model.

\section{Conclusion}

In this paper, I explore the role of self-employment in the recovery process from recessions. Four key facts

motivate my focus on self-employment and business cycle dynamics: self-employment is a pervasive feature of labor markets around the world; most self-employed run owner-only businesses with no salaried workers; and self-employment generally expands in recessions. I also document a robust negative relationship between the share of self-employment and the persistence of output over the business cycle in a sample of developed and developing countries. This link suggests that self-employment may be important for understanding differences in economic recoveries.

I build a business cycle model with frictional labor markets where individuals can be self-employed or work in salaried firms, and explore the channels through which self-employment influences the pace of recoveries. I find that economies with higher self-employment shares recover faster from negative aggregate productivity shocks. In the model, unemployed individuals who want to enter self-employment must match with capital suppliers in order to finance their business ventures. Salaried firms supply unused capital in the salaried sector to the self-employed in frictional capital markets. Capital search frictions play three key roles. First, they determine the availability of capital to the self-employed, thereby making transition rates into self-employment endogenous and dependent on aggregate economic conditions. Second, the supply and demand for self-employment capital create a direct link between conditions in self-employment and salaried wages. Third, access to self-employment, and therefore the self-employment outside option, changes in response to fluctuations in aggregate economic conditions. In particular, transition rates from unemployment into self-employment in the model expand in downturns, as in the data. This last fact is difficult to obtain in existing business cycle models of entrepreneurship and liquidity constraints. 
One contribution of my paper is to reconcile the fact that the self-employed require external resources to produce with the empirical evidence on the countercyclicality of self-employment. Furthermore, the model I propose is consistent with other stylized facts about self-employment and labor market dynamics.

Since self-employment is an alternative to salaried employment, cyclical movements in the ease of entry into self-employment affect salaried wages directly. Furthermore, the average level of self-employment in the economy determines how much the self-employment outside option influences the response of wages at the onset of a downturn, as well as the path of wages in the aftermath of a negative aggregate shock. When a negative aggregate shock hits the economy, wages in the salaried sector are initially more rigid in economies with higher average self-employment. These economies exhibit larger drops in vacancies, investment, and output, thereby generating sharper contractions. As aggregate productivity begins to recover, the availability of self-employment capital falls, which weakens the self-employment outside option much faster in these economies. This causes more persistent, or long-lasting, salaried wage contractions in economies with more self-employment, which creates a faster recovery in salaried employment and investment as salaried firms post vacancies and invest at a faster rate. Salaried output recovers faster, and this drives the faster recovery in total output in economies with higher average self-employment rates. The model helps us identify a subtle channel through which the long-run level of self-employment has implications for the economy's speed of recovery from downturns. In addition, the dynamic behavior of unemployment, investment, and output in response to shocks is consistent with the empirical evidence on business cycles in developed and developing economies.

The model goes a long way in capturing the relationship between the autocorrelation of output and the share of self-employment observed in the data. I find that allowing for a sectoral shock to self-employment productivity is important to capturing this relationship quantitatively. Furthermore, the inclusion of the shock allows the model to capture two additional stylized facts in the data: the higher output volatility in economies with more self-employment, and the higher volatility in self-employment earnings relative to wage earnings, which is consistent with empirical evidence on the higher riskiness and volatility in the self-employment sector. More broadly, this paper suggest that it is critical to account for the fact that the likelihood of entering into self-employment - and hence the self-employment outside option - is not fixed but rather fluctuates with the aggregate state of the economy. Existing models have ignored this relevant cyclical feature of self-employment. Movements in the attractiveness of, and ease of entry into, self-employment over the business cycle - which are ultimately affected by the structure of the labor market - feed into the decisions of agents in the salaried sector, with important consequences for economic recoveries and business cycle dynamics. 
The model does not differentiate between high and low-ability self-employed individuals, which prevents me from capturing other very relevant features of self-employment highlighted in the empirical literature, such as the fact that a proportion of the self-employed enter the sector during economic expansions and expand their firms by creating salaried positions. It would be particularly interesting to incorporate this heterogeneity in the current version of the model and address business cycle dynamics and firm growth simultaneously. For example, we would be able to explore the policy implications of promoting small firm creation during downturns. It would also allow us to investigate whether targeting small firm creation based on observables such as the human capital of firm owners matters for the policy's success. This framework would be relevant even for countries like the U.S. since a large majority of the self-employed tend to be own-account workers. Relatedly, the fact that agents are perfectly insured within the household - a common assumption in labor search models - prevents me from appropriately addressing the relevance of higher riskiness in self-employment. In principle, the higher volatility of self-employment earnings should arise endogenously due to occupational choice risk, production risk, or other characteristics that are determined within the economic environment, and should not rely on an exogenous process as is currently the case in the model. Indeed, some of the benefits from self-employment may be reduced once we take into account the risk involved in entering the sector. Also, to the extent that risk and uncertainty may increase in recessions, the model might yield an incomplete picture of the actual behavior of the self-employed. Finally, while the existing evidence on trade credit supported the use of capital search frictions as a reduced-form modeling device, there is little empirical work done in this area. The increasing availability of surveys that capture the obstacles faced by micro-firms in developing countries provides an exciting avenue that can take us deeper into the frictions that affect firm creation over the business cycle. Much remains to be understood about the cyclical implications of differences in the structure of labor markets. Taking these shortcomings into account, this paper offers a framework that incorporates selfemployment in a tractable way to help us deepen our understanding of the link between business cycle dynamics and the composition of employment. I plan to explore the limitations and extensions outlined above in future work. 


\section{Appendix}

\subsection{Summary Statistics and Relationship Between Self-Employment and Output Per- sistence}

Table 6: Cross-Country Descriptive Statistics: Full Sample

\begin{tabular}{ccccccc}
\hline \hline Variable & Years & Obs. & Mean & SD & Min. & Max. \\
\hline SE Rate & $2000-2007$ & 86 & 31.8 & 20.72 & 5.00 & 88.7 \\
AC of Output & $1985-2007$ & 115 & 0.519 & 0.206 & -0.245 & 0.777 \\
Log Real GDP 1985 & 1985 & 115 & 23.4 & 2.24 & 18.9 & 29.4 \\
\hline
\end{tabular}

AC of Output refers to the autocorrelation of the cyclical component of output. SE refers to SelfEmployment. I use Catini, Panizza, and Saade's (2010) compilation of the World Bank's World Development Indicators (WDI) to obtain the annual series for PPP-adjusted real GDP for each country from 1985 to 2007. I HP-filter the series with a smoothing parameter of 100 to extract the cyclical component of the series and compute the first-order autcorrelation, which I take to be the measure of cyclical persistence in the paper. Self-employment is obtained from the OECD (2009) and corresponds to the average share of self-employed individuals in non-agricultural employment for years 2000 through 2007. Self-employment includes own-account workers, employers, and contributing family members. Figure 1 in the text uses 83 observations and excludes countries with an autocorrelation of output lower than 0.1.

The estimation equation for the persistence of the cyclical component of real GDP can be written as

$$
A C\left(G D P_{i}\right)=\gamma_{0}+\gamma_{1} S E_{i}+\sum_{k=2}^{n} \gamma_{k} X_{k_{i}}+\mu_{i}
$$

Where $A C\left(G D P_{i}\right)$ denotes the first-order autocorrelation of the cyclical component of the log of real GDP in country $i . S E_{i}$ is the average self-employment rate as share of non-agricultural employment for years 2000 through 2007, $\mu_{i}$ is an error term, and $X_{k_{i}}$ encompasses other regressors of interest including a measure of openness over the sample period, the log of real GDP per capita in 1985 as a proxy for the country's level of development, the government spending-to-GDP ratio over the sample period, and a measure of the quality of institutions (Law and Order from Political Risk Services, PRS). ${ }^{53}$ Openness

\footnotetext{
${ }^{53}$ All these variables except for log real GDP per capita in 1985 and Law and Order are averages from 1985 to 2007. I also experiment with log real GDP in 1985, which has a lower correlation with self-employment, when excluding institutional quality and obtain qualitatively similar results.
} 
Table 7: Self-Employment and Cyclical Persistence: Cross-Country Evidence

\begin{tabular}{|c|c|c|c|c|c|}
\hline Dep. Variable: & & Autocorrel. & of & Output & \\
\hline Specification & $(1)$ & $(2)$ & $(3)$ & $(4)$ & $(5)$ \\
\hline Self-Employment & $-0.003^{* * *}$ & $-0.003^{* *}$ & $-0.003^{* *}$ & $-0.003^{* *}$ & $-0.004^{* * *}$ \\
\hline Log RGDP 1985 & - & 0.015 & 0.015 & 0.013 & - \\
\hline Openness & - & - & $-0.000^{* *}$ & $-0.000^{* *}$ & $-0.000^{*}$ \\
\hline Gov. Spending & - & - & - & -0.002 & -0.002 \\
\hline Law and Order & - & - & - & - & -0.001 \\
\hline $\operatorname{Adj} \cdot R^{2}$ & 0.14 & 0.17 & 0.20 & 0.20 & 0.21 \\
\hline Obs. & 83 & 82 & 82 & 82 & 78 \\
\hline
\end{tabular}

Note: The results above use the sample for self-employment with 83 observations, which excludes countries with an autocorrelation of output lower than 0.1 .

is defined as the sum of imports and exports divided by GDP. All the regressors except for the selfemployment rate and Law and Order are taken from the World Development Indicators (WDI) for years 1985 through 2007. The results in Table B2 omit the constant term in the regression for expositional purposes. As the table shows, the coefficient on self-employment is significant at conventional levels and fairly stable across specifications. ${ }^{54}$ Eliminating potential outliers (countries with autocorrelations less than 0.2 and countries with a share of self-employment higher than 85 percent) reduces the coefficient on self-employment only slightly. However, the results are still significant at conventional levels and remain essentially the same. Restricting the sample to developing countries does not change the main conclusions either.

While the level of income and the quality of institutions are considered important determinants of self-employment in the literature, it is important to assess how controlling for these two factors affects the results. After all, institutional quality might influence the persistence of cyclical output in other ways unrelated to this variable's impact on self-employment. Table B2 shows that the significance of selfemployment holds for all specifications, with little variation in the coefficient value. Using a smoothing

\footnotetext{
${ }^{54}$ For now, I ignore the possibility that self-employment might be influenced by the persistence of output, though it is not strictly correct to claim causation from self-employment to output persistence without taking care of the potential endogeneity between the two variables. One piece of evidence regarding entrepreneurship that acts in favor of the approach I present here is that, while the business cycle might affect entry into self-employment over the life-cycle, this effect seems to be temporary and only delays entry into entrepreneurship (see, for example, $\mathrm{Yu}$, Orazem, and Jolly, 2009). Thus, the deep determinants of self-employment are likely to be less dependent on short-run economic activity and more dependent on other structural features of the economy.
} 
parameter of 6.25 to extract the cyclical component of output, which is another common value used in the literature, does not alter the qualitative results or the strength of the relationship between the cyclical persistence of output and self-employment. The measure of self-employment I use only considers self-employment in non-agricultural employment. Since developing countries have large self-employment shares in agriculture as well, one may wonder whether the link between self-employment and output persistence over the business cycle still holds when we control for the share of employment in agriculture or the share of agricultural production in GDP. The sign and significance of the relationship remain virtually unchanged when I control for either one of these measures. ${ }^{55}$ Finally, the results remain qualitatively the same if I use non-agricultural real GDP as opposed to total real GDP to compute the measure of cyclical persistence. ${ }^{56}$

\subsection{Derivation of Nash Wage and Rental Rate Equations}

Recall that the value functions for the household and the salaried firm are given by:

$$
\begin{gathered}
\mathbf{W}_{S, t}=\lambda_{t}^{h} w_{S, t}+E_{t} \beta\left\{\left(1-\delta^{S}\right) \mathbf{W}_{S, t+1}+\delta^{S} \mathbf{W}_{U, t+1}\right\} \\
\mathbf{W}_{S E, t}=\lambda_{t}^{h}\left(z_{t} a_{S E, t}-r_{S E, t}\right)+E_{t} \beta\left\{\left(1-\delta^{S E}\right) \mathbf{W}_{S E, t+1}+\delta^{S E} \mathbf{W}_{U, t+1}\right\} \\
\mathbf{W}_{U, t}=\lambda_{t}^{h} b+E_{t} \beta\left\{\begin{array}{c}
\left(1-\delta^{S}\right) p\left(\theta_{S, t}\right) \mathbf{W}_{S, t+1} \\
+\left(1-\delta^{S E}\right) p\left(\theta_{S E, t}\right) \mathbf{W}_{S E, t+1} \\
+\left[1-\left(1-\delta^{S}\right) p\left(\theta_{S, t}\right)\right. \\
\left.-\left(1-\delta^{S E}\right) v_{S E, t}^{u} p\left(\theta_{S E, t}\right)\right] \mathbf{W}_{U, t+1}
\end{array}\right\} \\
\mathbf{J}_{S, t}=z_{t} a_{S} f_{n_{S}}\left(n_{S, t}, \omega_{t} k_{S, t}\right)-w_{S, t}+E_{t} \Xi_{t+1 \mid t}\left\{\left(1-\delta^{S}\right) \mathbf{J}_{S, t+1}\right\} \\
\mathbf{J}_{S E, t}=r_{S E, t}+\left(\delta^{S E}-\delta\right)+E_{t} \Xi_{t+1 \mid t}\left\{\left(1-\delta^{S E}\right) \mathbf{J}_{S E, t+1}\right\}
\end{gathered}
$$

Where $\Xi_{t+1 \mid t}=\beta\left(\frac{U_{c}\left(c_{t+1}\right)}{U_{c}\left(c_{t}\right)}\right)$ and $\lambda_{t}^{h}=U_{c}\left(c_{t}\right)$. The Nash bargaining first-order condition for the wage is given by

$$
\left(\frac{\mathbf{W}_{S, t}-\mathbf{W}_{U, t}}{\lambda_{t}^{h}}\right)=\frac{\nu_{S}}{1-\nu_{S}}\left(\mathbf{J}_{S, t}\right)
$$

\footnotetext{
${ }^{55}$ The share of employment in agriculture and the share of agricultural production in GDP are highly correlated with initial GDP per capita. A similar comment applies to the proxy for institutional quality, Law and Order. Thus, when I regress output persistence on the share of non-agricultural self-employment, I exclude initial GDP per capita as well as Law and Order.

${ }^{56} \mathrm{In}$ fact, the relationship between self-employment and the cyclical persistence of non-agricultural output is still negative, but becomes stronger.
} 
For the rental rate on capital used in self-employment, we have

$$
\left(\frac{\mathbf{W}_{S E, t}-\mathbf{W}_{U, t}}{\lambda_{t}^{h}}\right)=\frac{\nu_{S E}}{1-\nu_{S E}}\left(\mathbf{J}_{S E, t}-\mathbf{J}_{u_{k}, t}\right)
$$

First, write

$$
\begin{aligned}
\left(\mathbf{W}_{S E, t}-\mathbf{W}_{U, t}\right)= & \left(z_{t} a_{S E, t}-r_{S E, t}\right)-b \\
& +E_{t} \Xi_{t+1 \mid t}\left\{\begin{array}{c}
\left(1-v_{S E, t}^{u} p\left(\theta_{S E, t}\right)\right)\left(1-\delta^{S E}\right) \\
\times\left(\mathbf{W}_{S E, t+1}-\mathbf{W}_{U, t+1}\right) \\
-p\left(\theta_{S, t}\right)\left(1-\delta^{S}\right)\left(\mathbf{W}_{S, t+1}-\mathbf{W}_{U, t+1}\right)
\end{array}\right\}
\end{aligned}
$$

Similarly, we can write

$$
\begin{aligned}
\left(\mathbf{W}_{S, t}-\mathbf{W}_{U, t}\right)= & w_{S, t}-b \\
& +E_{t} \Xi_{t+1 \mid t}\left\{\begin{array}{c}
\left(1-p\left(\theta_{S, t}\right)\right)\left(1-\delta^{S}\right)\left(\mathbf{W}_{S, t+1}-\mathbf{W}_{U, t+1}\right) \\
-v_{S E, t}^{u} p\left(\theta_{S E, t}\right)\left(1-\delta^{S E}\right)\left(\mathbf{W}_{S E, t+1}-\mathbf{W}_{U, t+1}\right)
\end{array}\right\}
\end{aligned}
$$

Using the first-order conditions from Nash bargaining, we have:

$$
\begin{aligned}
& \frac{\nu_{S E}}{1-\nu_{S E}}\left(\mathbf{J}_{S E, t}-\mathbf{J}_{u_{k}, t}\right)=\left(z_{t} a_{S E, t}-r_{S E, t}\right)-b+ \\
& E_{t} \Xi_{t+1 \mid t}\left\{\begin{array}{c}
\frac{\nu_{S E}\left(1-v_{S E, t}^{u} p\left(\theta_{S E, t}\right)\right)}{1-\nu_{S E}}\left(1-\delta^{S E}\right) \\
\times\left(\mathbf{J}_{S E, t+1}-\mathbf{J}_{u_{k}, t+1}\right) \\
-\frac{p\left(\theta_{S, t}\right) \nu_{S}}{1-\nu_{S}}\left(1-\delta^{S}\right) \mathbf{J}_{S, t+1}
\end{array}\right\}
\end{aligned}
$$

and

$$
\frac{\nu_{S}}{1-\nu_{S}}\left(\mathbf{J}_{S, t}\right)=w_{S, t}-b+E_{t} \Xi_{t+1 \mid t}\left\{\begin{array}{c}
\frac{\left(1-p\left(\theta_{S, t}\right)\right) \nu_{S}}{1-\nu_{S}}\left(1-\delta^{S}\right) \mathbf{J}_{S, t+1} \\
-\frac{\nu_{S E} v_{S E, t}^{u} p\left(\theta_{S E, t}\right)}{1-\nu_{S E}}\left(1-\delta^{S E}\right) \\
\times\left(\mathbf{J}_{S E, t+1}-\mathbf{J}_{u_{k}, t+1}\right)
\end{array}\right\}
$$

Using the optimality conditions from the firm's and household's problems, we can write:

$$
\frac{\psi_{S}}{q\left(\theta_{S, t}\right)}=E_{t} \Xi_{t+1 \mid t}\left\{\left(1-\delta^{S}\right) \mathbf{J}_{S, t+1}\right\}
$$

and

$$
\frac{\left[z_{t} a_{S} f_{\omega k_{S}}\left(n_{S, t}, \omega_{t} k_{S, t}\right)+\left(1-\delta^{S E}\right) q\left(\theta_{S E, t}\right)\right]}{q\left(\theta_{S E, t}\right)}=E_{t} \Xi_{t+1 \mid t}\left\{\left(1-\delta^{S E}\right) \mathbf{J}_{S E, t+1}\right\}
$$


Recall that $\Xi_{t+1 \mid t}=\frac{\beta \lambda_{t+1}^{h}}{\lambda_{t}^{h}}=\frac{\beta U_{c}\left(c_{t+1}\right)}{U_{c}\left(c_{t}\right)}, \frac{p\left(\theta_{S, t}\right)}{q\left(\theta_{S, t}\right)}=\theta_{S, t}, \frac{p\left(\theta_{S E, t}\right)}{q\left(\theta_{S E, t}\right)}=\frac{1}{\theta_{S E, t}}$, and $\mathbf{J}_{u_{k}, t}=(1-\delta)$. After some algebra and using the three facts above along with $\lambda_{t}^{h}=U_{c}\left(c_{t}\right)$, we obtain expressions for $w_{S, t}$ and $r_{S E, t}$ :

$$
\begin{aligned}
& w_{S, t}=\nu_{S}\left[z_{t} a_{S} f_{n_{S}}\left(n_{S, t}, \omega_{t} k_{S, t}\right)+\psi_{S} \theta_{S, t}\right]+\left(1-\nu_{S}\right) b \\
& +\quad \frac{\left(1-\nu_{S}\right) \nu_{S E}}{1-\nu_{S E}} v_{S E, t}^{u} p\left(\theta_{S E, t}\right)\left[\frac{z_{t} a_{S} f_{\omega k_{S}}\left(n_{S, t}, \omega_{t} k_{S, t}\right)}{q\left(\theta_{S E, t}\right)}\right] \\
& +\quad \frac{\left(1-\nu_{S}\right) \nu_{S E}}{1-\nu_{S E}} v_{S E, t}^{u} p\left(\theta_{S E, t}\right)\left(1-\delta^{S E}\right)\left[1-E_{t} \Xi_{t+1 \mid t}(1-\delta)\right] \\
& r_{S E, t}=\left(1-\nu_{S E}\right)\left[z_{t} a_{S E, t}-\frac{\nu_{S}}{1-\nu_{S}} \psi_{S} \theta_{S, t}-b\right] \\
& -\quad \nu_{S E} v_{S E, t}^{u} p\left(\theta_{S E, t}\right)\left[\frac{z_{t} a_{S} f_{\omega k_{S}}\left(n_{S, t}, \omega_{t} k_{S, t}\right)}{q\left(\theta_{S E, t}\right)}\right] \\
& +\quad \nu_{S E}\left(1-v_{S E, t}^{u} p\left(\theta_{S E, t}\right)\right)\left(1-\delta^{S E}\right)\left[1-E_{t} \Xi_{t+1 \mid t}(1-\delta)\right]
\end{aligned}
$$




\section{References}

[1]

[2] Adjemian, Stéphane, Houtan Bastani, Michel Juillard, Ferhat Mihoubi, George Perendia, Marco Ratto and Sébastien Villemot. 2011. "Dynare: Reference Manual, Version 4," Dynare Working Papers, 1, CEPREMAP.

[3] Akyol, Ahmet, and Kartik Athreya. 2009. "Self-Employment Rates and Business Size: The Roles of Occupational Choice and Credit Frictions," Annals of Finance, Vol. 5, Numbers 3-4, pp. 495-519.

[4] Andolfatto, David. 1996. "Business Cycles and Labor-Market Search," American Economic Review, Vol. 86, pp. 112-132.

[5] Ardagna, Silvia, and Annamaria Lusardi. 2008. "Explaining International Differences in Entrepreneurship: the Role of Individual Characteristics and Regulatory Constraints," NBER Working Paper 14012.

[6] Arseneau, David, Sanjay K. Chugh, and André Kurmann. 2008. "Optimal Capital Taxation in an Economy with Capital Allocation Frictions," mimeo.

[7] Bargain, Olivier, and Prudence Kwenda. 2010. "Is Informality Bad? Evidence from Brazil, Mexico, and South Africa," IZA Discussion Paper No. 4711.

[8] Bargain, Olivier, Eliane El Badaoui, Prudence Kwenda, Eric Strobl, and Frank Walsh. 2012. "The Formal Sector Wage Premium and Firm Size for Self-Employed Workers," IZA Discussion Paper No. 6604 .

[9] Bartelsman, Eric, John Haltiwanger, and Stefano Scarpetta. 2013. "Cross-Country Differences in Productivity: The Role of Allocation and Selection." American Economic Review, Vol. 103, No. 1, pp. 305-334.

[10] Beck, Thorsten, Asli Demirgüç-Kunt, and Vojislav Maksimovic. 2008. "Financing Patterns around the World: Are Small Firms Different?" Journal of Financial Economics 89 (3), pp. 467-487. 
[11] Berg, Janine, and Sandrine Cazes. 2007. "The Doing Business Indicators: Measurements Issues and Political Implications," Economic and Labour Market Paper 2007/06, International Labour Organization.

[12] Bergoeing, Raphael, Norman Loayza, and Andrea Repetto. 2004. "Slow Recoveries," Journal of Development Economics, Vol. 75, pp. 473-506.

[13] Blanchflower, David G. 2004. "Self-Employment: More May Not Be Better," NBER Working Paper No. 10286.

[14] Bosch, Mariano, and Julen Esteban-Pretel. 2006. "The Informal Labor Market in Latin America," mimeo.

[15] Bosch, Mariano, and Julen Esteban-Pretel. 2009. "Cyclical Informality and Unemployment," mimeo.

[16] Bosch, Mariano, and Julen Esteban-Pretel. 2012. "Job Creation and Job Destruction in the Presence of Informal Labor Markets," Journal of Development Economics, Vol. 98, pp. 270-286.

[17] Bosch, Mariano, and William Maloney. 2006. "Gross Worker Flows in the Presence of Informal Labor Markets: Evidence from Mexico, 1987-2002," mimeo.

[18] Bosch, Mariano, and William Maloney. 2008. "Cyclical Movements in Unemployment and Informality in Developing Countries," mimeo.

[19] Bosch, Mariano, and William Maloney. 2010. "Comparative Analysis of Labor Market Dynamics Using Markov Processes: An Application to Informality,” Labour Economics, Vol. 17, pp. 621-631.

[20] Buera, Fransisco J., Joseph Kaboski, and Yongseok Shin. 2011. "Finance and Development: A Tale of Two Sectors." American Economic Review, Vol. 101, No. 5, pp. 1964-2002.

[21] Burkart, Mike, and Tore Ellingsen. 2004. "In-Kind Finance: A Theory of Trade Credit," American Economic Review, Vol. 94, No. 3, pp. 569-590.

[22] Calderón, Cesar, and Rodrigo Fuentes. 2010. "Characterizing the Business Cycles of Emerging Economies," Policy Research Working Paper 5343, The World Bank: Washington D.C. 
[23] Catini, Giulia, Ugo Panizza, and Carol Saade. 2010. "Macro Data 4 Stata," http://sites.google.com/site/md4stata/

[24] Chavis, Larry, Leora Klapper, and Inessa Love. 2010. "International Differences in Entrepreneurial Finance," Enterprise Note No. 11, Enterprise Note Series, The World Bank: Washington D.C.

[25] Chavis, Larry, Leora Klapper, and Inessa Love. 2011. "The Impact of the Business Environment on Young Firm Financing," World Bank Economic Review, Vol. 25, No. 3, pp. 486-507.

[26] Congregado, Emilio, Antonio A. Golpe, and Simon Parker. 2009. "The Dynamics of Entrepreneurship: Hysteresis, Business Cycles, and Government Policy," IZA Discussion Paper No. 4093.

[27] Cull, Robert, David McKenzie, and Christopher Woodruff. 2008. "Experimental Evidence on Returns to Capital and Access to Finance in Mexico," The World Bank Economic Review, Vol. 22, No. 3, pp. 457-482.

[28] Demirgüç-Kunt, Asli, and Vojislav Maksimovic. 2001. "Firms as Financial Intermediaries: Evidence from Trade Credit Data," Policy Research Working Paper 2696, The World Bank: Washington, D.C.

[29] den Haan, Wouter J., Garey Ramey, and Joel Watson. 2003. "Liquidity Flows and Fragility of Business Enterprises," Journal of Monetary Economics, Vol. 50, pp. 1215-1241.

[30] den Haan, Wouter J. and Georg Kaltenbrunner. 2009. "Anticipated Growth and Business Cycles in Matching Models," Journal of Monetary Economics, Vol. 56, pp. 309-327.

[31] Eisfeldt, Andrea L. and Adriano A. Rampini. 2009. "Leasing, Ability to Repossess, and Debt Capacity," Review of Financial Studies, Vol. 22, No. 4.

[32] Fabbri, Daniela, and Leora F. Klapper. 2009. "Trade Credit and the Supply Chain,” mimeo.

[33] Fiess, Norbert M., Marco Fugazza, and William F. Maloney. 2010. "Informal Self-Employment and Macroeconomic Fluctuations," Journal of Development Economics, Vol. 91, pp. 211-226.

[34] Gal, Peter N., and Gabor Pinter. 2013. "Capital over the Business Cycle: Renting versus Ownership," Bank of England Working Paper No. 478. 
[35] Galli, Rossana, and David Kucera. 2008. "Gender, Informality and Employment Adjustment in Latin America," Working Paper No. 85, Policy Integration and Statistics Department, International Labour Office, Geneva.

[36] Gollin, Douglas. 2008. "Nobody's Business but my Own: Self-Employment and Small Enterprise inEconomic Development," Journal of Monetary Economics, Vol. 55, Issue 2, pp. 219-233.

[37] Hall U., Luis J., and Alexander Monge-Naranjo. 2003. "Access to Credit and the Effect of Credit Constraints on Costa Rican Manufacturing Firms," Research Network Working Paper \#R-47 I, InterAmerican Development Bank: Washington D.C.

[38] Hamilton, Barton H. 2000. "Does Entrepreneurship Pay? An Empirical Analysis of the Returns of Self-Employment," Journal of Political Economy, Vol. 108, No. 3, pp. 604-631.

[39] Hobijn, Bart, and Ayşegül Şahin. 2007. "Firms and Flexibility," mimeo.

[40] Hopenhayn, Hugo A. 2012. "On the Measure of Distortions," mimeo.

[41] Hsieh, Chang-Tai and Peter J. Klenow. 2009. "Misallocation and Manufacturing TFP in China and India," Quarterly Journal of Economics, Vol. 124, Issue 4, pp. 1403-1448.

[42] Hurst, Erik, and Benjamin W. Pugsley. 2011. "What Do Small Businesses Do," mimeo.

[43] IDB. 2005a. "Unlocking Credit, The Quest for Deep and Stable Bank Lending," Research Department, Inter-American Development Bank: Washington D.C. http://www.iadb.org/res/ipes/2005/index.cfm.

[44] IDB. 2005b. "Developing Entrepreneurship: Experience in Latin America and Worldwide," Edited by Hugo Kantis, with collaboration of Pablo Angelelli and Virginia Moori Koenig, Inter-American Development Bank: Washington D.C. http://idbdocs.iadb.org/wsdocs/getdocument.aspx?docnum=834797.

[45] ILO. 2002. "Women and Men in the Informal Economy: A Statistical Picture," Employment Sector, International Labor Organization, International Labour Office: Geneva. 
[46] Johnson, Simon, Daniel Kaufmann, and Pablo Zoido-Lobatón. 1999. "Corruption, Public Finances and the Unofficial Economy," Policy Research Working Paper 2169, Washington, D.C., World Bank.

[47] Kalemli-Ozcan, Sebnem, and Bent E. Sorensen. 2012. "Misallocation, Property Rights, and Access to Finance: Evidence from Within and Across Africa," NBER Working Paper 18030.

[48] Klapper, Leora F., Luc Laeven, and Raghuram Rajan. 2011. "Trade Credit Contracts," NBER Working Paper No. 17146.

[49] Klapper, Leora F., and Dougles Randall. 2011. "Financial Crisis and Supply-Chain Financing," in Trade Finance During the Great Trade Collapse, The World Bank Group. Ed. Jean-Pierre Chauffour and Marien Malouche. ISBN: 978-0-8213-8748-1.

[50] Koellinger, P.D. and A.R. Thurik. 2009. "Entrepreneurship and the Business Cycle," Tinbergen Institute Discussion Paper TI 2009-032/3.

[51] Krause, Michael U., and Thomas A. Lubik. 2007. "On-the-Job Search and the Cyclical Dynamics of the Labor Market," ECB Working Paper Series No. 779.

[52] Kumar, Alok, and Herbert J. Schuetze. 2007. "Self-Employment and Labor Market Policies," Department Discussion Paper DDP0704, Department of Economics, Universtity of Victoria.

[53] Kuntchev, Veselin, Rita Ramalho, Jorge Rodríguez-Meza, Judy S. Yang. 2012. "What have we learned from the Enterprise Surveys regarding access to finance by SMEs?," Enterprise Analysis Unit of the Finance and Private Sector Development, The World Bank Group.

[54] Kurmann, André, and Nicolas Petrosky-Nadeau. 2007. "Search Frictions in Physical Capital Markets as a Propagation Mechanism," Working Paper 0\%-12, Centre Interuniversitaire sur le Risque, les Politiques Économiques et l'Emploi.

[55] Levy, Santiago. 2007. "Can Social Programs Reduce Productivity and Growth? A Hypothesis for Mexico," IPC Working Paper Series Number 37, Gerald R. Ford School of Public Policy, University of Michigan. 
[56] Loayza, Norman V., and Jamele Rigolini. 2006. "Informality Trends and Cycles," World Bank Policy Research Working Paper 4078.

[57] Loayza, Norman V., and Jamele Rigolini. 2011. "Informal Employment: Safety Net or Growth Engine?," World Development, Vol. 39, Issue 9, pp. 1503-1515.

[58] Love, Inessa, Lorenzo A. Preve, and Virginia Sarria-Allende. 2007. "Trade Credit and Bank Credit: Evidence from Recent Financial Crises," Journal of Financial Economics, Vol. 83, Issue 2, pp. 453469.

[59] Maloney, William F., Wendy V. Cunningham, and Mariano Bosch. 2004. "The Distribution of Income Shocks during Crises: An Application of Quantile Analysis to Mexico, 1992-95," World Bank Economic Review, Vol. 18, No. 2, pp. 155-174.

[60] Mandelman, Federico S., and Gabriel V. Montes-Rojas. 2009. "Is Self-Empoyment and MicroEntrepreneurship a Desired Outcome?," World Development, Vol. 37, No. 12, pp. 1914-1925.

[61] Margolis, David N., Lucas Navarro, and David A. Robalino. 2012. "Unemployment Insurance, Job Search and Informal Employment," IZA Discussion Paper No. 6660.

[62] McKenzie, David J., and Christopher Woodruff. 2006. "Do Entry Costs Provide an Empirical Basis for Poverty Traps? Evidence from Mexican Microenterprises," Economic Development and Cultural Change, Vol. 55,No. 1, pp. 3-42.

[63] McMillan, John, and Christopher Woodruff. 1999. "Interfirm Relationships and Informal Credit in Vietnam," Quarterly Journal of Economics, Vol. 114, No. 4, pp. 1285-1320.

[64] Moscoso Boedo, Hernan J., and Toshihiko Mukoyama. 2012. "Evaluating the Effects of Entry Regulations and Firing Costs on International Income Differences," Journal of Economic Growth, Vol. 17, Issue 2, pp. 143-170.

[65] Narita, Renata. 2010. "Self Employment in Developing Countries: a Search-Equilibrium Approach," PhD Dissertation, University College London. 
[66] Nicoletti, Giuseppe, and Olivier Pierrard. 2006. "Capital Market Frictions and the Business Cycle," mimeo.

[67] OECD. 2009. "Overview: Data on Informal Employment and Self-Employment," in Is Informal Normal? Towards More and Better Jobs in Developing Countries, OECD Development Centre, Ed. Johannes P. Jütting and Juan R. de Laiglesia.

[68] Petersen, Mitchell A., and Raghuram G. Rajan. 1997. "Trade Credit: Theories and Evidence," Review of Financial Studies, Vol. 10, Issue 3, pp. 661-691.

[69] Pietrobelli, Carlo, Roberta Rabellotti, and Matteo Aquilina. 2004. "An Empirical Study of the Determinants of Self-Employment in Developing Countries," Journal of International Development, Vol. 15 , pp. 803-820.

[70] Poschke, Markus. 2011. "The Firm Size Distribution Across Countries and Skill-Biased Change in Entrepreneurial Technology," mimeo.

[71] Quintin, Erwan, and Sangeeta Pratap. 2006. "The Informal Sector in Developing Countries: Output, Assets and Employment," mimeo.

[72] Ramey, Valerie A. 1992. "The Source of Fluctuations in Money: Evidence from Trade Credit," Journal of Monetary Economics, Vol. 30, pp. 171-193.

[73] Rissman, Ellen R. 2003. "Self-Employment as an Alternative to Unemployment," Federal Reserve Bank of Chicago Working Paper 2003-34.

[74] Rissman, Ellen R. 2007. "Labor Market Transitions and Self-Employment," Federal Reserve Bank of Chicago Working Paper 2007-14.

[75] Safavian, Mehnaz, and Joshua Wimpey. 2007. "When do Enterprises Prefer Informal Credit?" Policy Research Working Paper 4435, Financial and Private Sector Development, Enterprise Analysis Unit, The World Bank.

[76] Sanandaji, Tino. 2010. "Self-Employment Does Not Measure Entrepreneurship," The Institute for Industrial Economics, University of Chicago. 
[77] United Nations. 2008. "Non-Observed Economy in National Accounts: Survey of Country Practices," United Nations Economic Commission for Europe.

[78] Wasmer, Etienne, and Philippe Weil. 2004. "The Macroeconomics of Labor and Capital Market Imperfections," American Economic Review, 94(4), pp. 944-963.

[79] Worldwide Governance Indicators. 2012. The World Bank Group: Washington, D.C. URL http://info.worldbank.org/governance/wgi/resources.htm.

[80] Yu, Li, Peter F. Orazem, and Robert W. Jolly. 2009. "Stopping Start-Ups: How the Business Cycle Affects Entrepreneurship," Iowa State University Department of Economics Working Paper No. 09014. 